NASA Technical Memorandum 83639

\title{
Determination of Compressor In-Stall Characteristics from Engine Surge Transients
}

Carl F. Lorenzo, Francis P. Chiaramonte, and Charles M. Mehalic

Lewis Research Center

Cleveland, Ohio

Prepared for the

Twentieth Joint Propulsion Conference cosponsored by the AIAA, SAE, and ASME

Cincinnati, Ohio, June 11-13, 1984 


\title{
DETERMINATION OF COMPRESSOR IN-STALL CHARACTERISTICS FROM ENGINE SURGE TRANSIENTS
}

\author{
Carl F. Lorenzo, Francis P. Chiaramonte, \\ and Charles M. Mehalic \\ National Aeronautics Space Administration \\ Lewis Research Center \\ Cleveland, Ohio $\mathbf{4 4 1 3 5}$
}

\section{Abstract}

A technique for extracting the in-stall pumping characteristics for an axial flow compressor operating in an engine system environment is developed.

The technique utilizes a Hybrid computer simulation of the compressor momentum equation into which actual transient data are used to provide all terms but the desired compressor characteris$t$ ic. The compressor force characteristic as a function of corrected flow and speed result from the computation. The critical problem of data filtering is addressed.

Results for a compressor operating in a turbofan engine are presented and comparison is made with the conventional compressor map. The relationship of the compressor surge characteristic with its rotating stall characteristic is explored. Initial interpretation of the measured results is presented.

\section{Nomenclature}

A flow area

$F$ corner frequency, force

$G(s)$ filter transfer function

$g$ gravitational constant

K constant

$\ell$ compressor length

$\mathrm{N}$ rotor speed

$P$ pressure

$P R$ pressure ratio, $P_{3 T} / P_{2} T$

S laplace parameter

sgn sign of

$T$ temperature

$t$ time

$v$ velocity

$\mathscr{V}$ volume

W flow rate

o density

T time constant

\section{Subscripts}

\begin{tabular}{|c|c|}
\hline C & compressor \\
\hline CHAR & characteristic \\
\hline $\operatorname{cs}$ & control surface \\
\hline cV & control volume \\
\hline corr & corrected \\
\hline $\begin{array}{l}d \\
D\end{array}$ & $\begin{array}{l}\text { differentiator } \\
\text { dynamic derivative }\end{array}$ \\
\hline $\begin{array}{l}\text { ex } \\
f\end{array}$ & $\begin{array}{l}\text { external } \\
\text { friction }\end{array}$ \\
\hline$f$ & $\begin{array}{l}\text { friction linear } \\
\text { friction square law }\end{array}$ \\
\hline
\end{tabular}

\section{Introduction}

The understanding of turbomachinery compressor dynamic behavior is central to the stability modelling of turbine engine systems. This is especially true when considering the stagnation stall or hung stall phenomena manifested in some current engines. (1) In this situation a stall occurring in the compressor system is difficult or impossible to clear with normal control actions.

The ability to predict the stall stagnation or recovery processes requires detailed understanding of compressor dynamic behavior both in the stable (unstalled) zone and considerably offdesign, that is, in-stall and even into the compressor negative flow regime.

Numerous investigators have developed dynamic modelling procedures for axial flow compressors. (2-4) Typically these models are intended for use in full system models and are premised on actuator disk concepts. These concepts combine compressor steady state performance maps with the conservation equations written in a one dimensional form.

Usually in this type of modelling the momentum equation is written across either a stage or the complete compressor. The terms which go into the compressor momentum equation are the pressure-area terms, the flux of momentum terms, and the external force which is generated by the pumping action of the compressor. This is the sum of the internal forces applied to the compressed fluid. It is this forcing function supplied by the compressor in the dynamic sense which is to be determined. In the past, in order to make the momentum equation consistent with steady state data, the normal compressor map, that is pressure ratio versus flow (or a phi-psi map), was used to derive the force applied by the compressor to the fluid. Determination of this force in the dynamic sense is quite difficult.

The subject of this paper is to attempt to imply this instantaneous force based on experimental data. It is the premise of this paper that if a) 1 the terms required for the momentum equation with the exception of the instantaneous force applied to the fluid by the blades can be measured, then the instantaneous force can be implied by the momentum equation. This in turn can be related back to the desired compressor characteristic. A concept similar to this has been forwarded in an unpublished paper by Gamache $(5)$ in which some initial attempts to determine the compressor characteristics were implemented. This effort resulted in double valued compressor characteristics. 
The present paper attempts to establish a computational technique for determining the compressor instantaneous force from experimental data, to relate that force to the compressor in-stall characteristic, and to establish guidelines for data filtering. The paper will present typical results for data generated on a turbofan engine, examine the effects of compressor speed, examine the effects of filtering, and study the transition into rotating stall.

\section{Analytical Basis}

The analysis assumes an overall compressor model, that is, the conservation equations can be written across the entire compressor. It is, of course, also possible to consider the compressor on a stage-by-stage basis assuming that measurements can be made for all the inputs required as described above.

The one dimensional momentum equation for a fixed control volume can be written in the following form (for example, see ref. 6).

$$
\begin{gathered}
\sum F_{\text {ex }}=\int_{C V} \frac{\partial}{\partial t}\left(\rho V_{x}\right) d V+\int_{C S} \rho V_{N} V_{x} d A_{\text {out }} \\
-\int_{C S} \rho V_{N} V_{x} d A_{\text {in }}
\end{gathered}
$$

The external forces in this equation are as shown in Fig. 1, include the pressure-area terms acting on the front and rear faces of the compressor fluid, and a net force (called the instantaneous force) $F_{X}$ is applied to the fluid by the blades, wall, etc. For the compressor configuration, assuming one dimensional planar flow, i.e., $V_{N}=V_{X}$ and noting

$$
\frac{\partial}{\partial t} \int_{C V} \rho V_{x} d \mathscr{V}=\frac{d}{d t} \rho V_{x} \mathscr{V}=\frac{\ell}{g} \frac{d \dot{W}_{C}}{d t}
$$

and

$$
\int_{C S} \rho V_{N} V_{x} d A=\rho A V_{x}^{2}
$$

Then the momentum equation becomes

$$
\begin{aligned}
\sum F_{e x}=P_{2 S} A_{2} & -P_{3 S} A_{3}+F_{x}=\frac{\ell}{g} \frac{d W_{C}}{d t} \\
& +\rho_{3} A_{3} V_{3}{ }^{2}-\rho_{2} A_{2} V_{2}^{2}
\end{aligned}
$$

Now for low Mach numbers, total pressure can be approximated as

$$
P_{T}=P_{S}+\frac{1}{2} \rho V^{2}
$$

$$
\begin{aligned}
\frac{\ell}{g} \frac{d \dot{W} c}{d t}=P_{2} T^{A_{2}}-P_{3} T_{3}+ & F_{x}+\frac{1}{2} \rho_{2} A_{2} V_{2}^{2} \\
& -\frac{1}{2} \rho_{3} A_{3} V_{3}^{2}
\end{aligned}
$$

Neglecting the residual $1 / 2$ oAV 2 terms at low Mach number gives

$$
\frac{\ell}{\mathrm{g}} \frac{\mathrm{d} \dot{W}_{C}}{\mathrm{dt}}=P_{2 T} A_{2}-P_{3 T} A_{3}+F_{x}
$$

as the working form of the momentum equation. Note it is possible to relax some of the above assumptions if both static and total pressures are used, this is derived in Appendix A. Solving for the external instantaneous force acting on the fluid gives

$$
F_{x}=P_{3 T} A_{3}-P_{2 T} A_{2}+\frac{\ell}{g} \frac{d \dot{W}_{c}}{d t}
$$

Some investigators notably Grietzer, (2) hypothesize that at least in the transition from surge to rotating stall, additional dynamics occur between the steady-state characteristic and the instantaneous force. For the rotating stall case this is the time required for the stall cell growth to occur. A simple first order lag is assumed to represent these dynamics, thus:

$$
{ }^{\tau} C \frac{d F_{x}}{d t}+F_{x}=F_{m}
$$

determines the instantaneous force from the so called steady-state force $F_{m}$. A block diagram for the compressor model with this dynamic element assumed to be a first order lag is shown in Fig. 2. It is not clear that ${ }^{\mathrm{C}} \mathrm{C}$ has a value other than zero for a pure surge condition. (Surge data is to be analyzed.)

Assuming the above model applies, the instan$t$ aneous force $F_{X}$ can be implied from $\mathrm{Eq}$. (8). Two assumptions are implicit in this calculation, these are: (a) the flow is predominately onedimensional (uniform and planar) i.e., without rotating stall or secondary flows, and (b) that the flow throughout the compressor can be approximated by a single measurement, i.e. integration over the control volume is not necessary. If

$P_{3 T}, P_{2 T}$, and $W_{c} c$ an be actually measured as functions of time for a compressor operating in surge, then $F_{X} c$ an be determined as shown in the simplified block diagram of Fig. 3. Also, in this figure, the inverse dynamics of $\mathrm{Eq}$. (9) is applied to $F_{X}$ to determine $F_{m}$. Both $F_{X}$ and $F_{m}$ are shown plotted against $\dot{W}_{C}$, corr which is assumed to be the basis of correlation.

The actual calculation to determine the forces $F_{x}$ and $F_{m}$ is more involved than Fig. 3 indicates because: (a) it is possible that

Thus the momentum equation becomes 
the real data is not pure surge but is contaminated by either rotating stall or other multidimensional flow effects, (b) the real measurements can be contaminated by instrument or recording noise, (c) pure differentiations of the data tend to amplify the high frequency content (noise) and must, therefore, be approximated (filtered) and finally (d) several measurements may be required to replicate each of the signals that serve as inputs to the calculation.

With respect to the rotating stall issue, if rotating stall is present during the surge its effect may sometimes be removed from the data by careful filtering. This requires low-pass filters to be applied to the signals representing the measured variables prior to manipulation in calculating $F_{X}$ and $F_{m}$. These filters, if used, must have sufficient bandwidth to allow the highest harmonics present from the surge phenomenon to pass without significant loss. Simultaneously the filter corner frequency must be sufficiently below the rotating stall frequency to provide attenuation. Filters are also required to eliminate or minimize instrument noise and as a part of the differentiation process. The subject of filter placement and selection will be discussed in detail in a later section.

Relative to item D) above for a onedimensional reversing flow field two measurements are required for each total pressure; i.e., forward and aft facing. Thus as flow direction switches, the measurement read as total pressure must also switch. Also, corrected flow is computed from a Tee probe or Mach probe using appropriate flow calibrations.

Combining the above considerations, the computation for the instantaneous force, $F_{X}$, and the map force, $F_{m}$, for the most general case will appear as shown in Fig. 4. In this block diagram, the input filters, $G_{i}(s)$, following the measurement have the function to minimize the contamination by noise and effects of rotating stall. The output filters, $G_{0}(s)$, are always chosen as matched pairs and serve to help eliminate noise on the plotted signals. Also, practical differentiators have associated with them, built-in filters to limit amplification of high frequency noise. All filters used in this study are first order lags, i.e.,

$$
G(s)=\frac{\operatorname{Xout}(s)}{\operatorname{Xin}(s)}=\frac{1}{\tau s+1}
$$

where $s$ is the Laplace parameter, and $\tau$ is the filter time constant. The values chosen for the filter time constants will be discussed in a separate section.

It is the basic block diagram, Fig. 4, which is implemented on a hybrid computer and used to determine the compressor characteristic. The required input dynamic signals are recorded on FM magnetic tape, and trunked directly to the computer.

\section{Steady-State Relationships}

The relationship between the force characteristic $F_{X}$ or $F_{m}$, and the normal compressor map, pressure ratio versus corrected flow, may be determined by examining Eqs. (8) and (9). At steady-state conditions the derivative terms in these equations become zero, thus, $F_{m}=F_{x}$ and,

$F_{x}=P_{3 T} T_{3}-P_{2} T_{2}=P_{2 T} T_{2}\left[\left(\frac{P_{3 T}}{P_{2 T}}\right)\left(\frac{A_{3}}{A_{2}}\right)-1\right]$

Hence the normal compressor map characteristic (at constant speed) can be expressed as

$$
\left(\frac{P_{3 T}}{P_{2 T}}\right)_{C H A R}=\left(\frac{F_{x}}{P_{2 T} T_{2}}+1\right) \frac{A_{2}}{\frac{A_{3}}{T}}
$$

Here the subscript CHAR is added to differentiate between the characteristic and the dynamic pressure ratio. In actual practice, only very small differences in $\left(P_{3 T} / P_{2 T}\right)$ CHAR are seen between taking $\mathrm{P}_{2} \mathrm{~A}_{2}$ at its steady value or dynamic value in the division $F_{x} / P_{2 T} A_{2}$.

It "can be seen from these equations that, the $F_{x}$ characteristic is only a scale factor and constant translation different from the compressor map characteristic.

\section{Nature of Instantaneous Force}

The instantaneous force $F_{x}$ (fig. 5) can be thought of as being composed of three parts which are: (1) $F_{W}$, the force of the wall on the fluid, (2) $F_{f}$, the frictional force acting on the fluid and (3) $F_{D}$ the dynamic force applied to the fluid by virtue of the blade rotation. These forces may be considered as analogous to electrical voltages in a circuit, that is; FD is similar to a generated force, $F_{f}$ is analogous to a resistive force and $F_{W}$, may be thought of as a back EMF or reactive force. Thus,

$$
F_{x}=F_{D}-F_{f}-F_{w}
$$

Now the wall force may be approximated by

$$
F_{W}=\frac{1}{2}\left(P_{2 S}+P_{3 S}\right)\left(A_{2}-A_{3}\right)
$$

For linear friction

$$
F_{f \ell}=K_{f \ell} \dot{W}_{c}
$$

or for square law friction

$$
F_{f s}=K_{f s} \operatorname{sgn}\left(\dot{W}_{c}\right) \dot{W}_{c}^{2}
$$

For the linear friction case and using Eq. 8, the blade force, $F_{D}$ may be found as

$$
\begin{aligned}
F_{D}=P_{3 T} A_{3}-P_{2 T} A_{2}+\frac{1}{2}\left(P_{2 S}\right. & \left.+P_{3 S}\right)\left(A_{2}-A_{3}\right) \\
& +K_{f \ell} \dot{W}_{C}+\frac{\ell}{g} \frac{d \dot{W}_{C}}{d t}
\end{aligned}
$$

Or, if the differences between total and static pressure is ignored and letting $\bar{A}=\left(A_{2}+A_{3}\right) / 2$ 


$$
F_{D}=P_{3 T} \bar{A}-P_{2 T} \bar{A}+K_{f \ell} \dot{W}_{C}+\frac{\ell}{g} \frac{d \dot{W}_{C}}{d t}
$$

If $\mathrm{K}_{\mathrm{fe}}$ is known or $\mathrm{c}$ an be estimated these equations (eq. (17) or (18)) can be used to gain an insight to the nature of the instantaneous dynamic force. This has not been done in the current study.

\section{Experimental Aspects}

The data used in this study result from a single test run performed on a multi-stage axial flow compressor in a turbofan engine which was tested in the Propulsion System Laboratory of the NASA-Lewis Research Center. Under altitude conditions (inlet pressure of approximately $1 / 2$ atmosphere) the normal control for the engine was over-ridden and a large triangular fuel flow pulse was introduced into the combustor.

This pulse forced the engine into a surgelike instability which was allowed to continue (approx $32.5 \mathrm{sec)}$ until the compressor settled into rotating stall (a stagnation stall) condition. An overview of this transient is shown in Fig. 6 where compressor discharge static pressure $P_{3 S}$, interturbine temperature ITT, core mechanical' speed $N_{c}$ and power lever angle PLA are plotted versus time. The fuel pulse which causes the surge is not shown but lasts about $1 / 2$ second into the transient after which normal control is resumed.

That the compressor is in rotating stall after $t=32.5$ seconds is determined by power spectral analysis of data from circumferentially located pressure transducers at a common axial location (compressor inlet) which indicate appropriate phase differences. The rotating stall frequency is about 0.41 times the rotor speed, starting at about $91.3 \mathrm{~Hz}$ and decreasing with time and speed. Steady state and dynamic pressure and temperature instrumentation were available both upstream and downstream of the compressor.

Interstage wall static pressures were also measured. Some of the internal pressures in the compressor during the surge process are shown in Fig. 7. Here the transition from stable flow into surge (at approx $370 \mathrm{msec}$ ) is presented. From this figure it appears that the stall originates near the 8 th stage based on the pressure increase in all upstream stages at stall inception. Also the character (and frequency) of the first three stall cycles are different from the following two cycles. The frequency associated with the first stalls is about $10.7 \mathrm{~Hz}$ while that for the next two (and most of those that follow) is about 5.2 $\mathrm{Hz}$. During the time periods $A$ and $B$ of Fig. 7 , all the engine measurements are steady (not time varying) except those in the fuel control. It is assumed from this that the engine is essentially "recovered" but that a control instability (called a mode I instability in the remainder of the paper) forces a repeated stall/recovery cycle. The first cycles $(10.7 \mathrm{~Hz})$ are considered to be a classical surge, and will be called a mode II instability.

It is noted that the frequency of mode II is approximately two times the frequency of mode $I$.
By far most of the cycles seen in this transient are of the mode I type. Mode II, surge instability, is seen at the beginning of the transient, at the transition from surge into rotating stall and only very sporadically during the long transient. The frequencies of both modes increase by about $0.5 \mathrm{~Hz}$ over the duration of the run.

\section{Instrumentation and Data Acquisition}

In order to achieve high dynamic response pressure measurements, miniature pressure transducers were used. These solid state transducers are subject to significant zero shift with temperature. Thus, the instruments were water cooled and separate, stable lower response instruments are used to measure the steady (DC) level. The pressure signals analyzed are composites which are the sum of the DC signal, taken at a steady period just prior to the transient and the high response signal less its steady part at the same reference time. In spite of these precautions small additional $D C$ offsets are found to exist in the data. To account for this, at a single speed $(N=77 \%)$ minor corrections are made to the DC level of the signals so that the recovered periods $A$ and $B$ of Fig. 7 agree with a corresponding steady period on the normal compressor map. High response, 0.003 inch diameter thermocouples were used for temperature measurements. Corrected flow was measured with specially calibrated fore and aft facing total pressure (TEE) probes.

Al1 dynamic measurements were recorded on magnetic tape using an FM multiplex system. A maximum of 14 of these signals were demultiplexed and recorded on a second analog magnetic tape which was used for the data analysis. Due to data reduction hardware limitations not a 11 desired combinations of signals were possible.

\section{Results}

Prior to applying the above analytical procedures to determine the compressor force characteristic from engine surge data a spectral analysis is performed on the available measurements. A typical spectral plot of compressor discharge pressure, $P_{3 T}$, over the entire transient being used is presented in Fig. 8. Each line in the figure represents 2 seconds of data. The spectral analysis indicates that there is no rotating stall present during the surge phenomena. Here the first 16 lines (32 seconds) of the graph show the surge ( $p l a n a r)$ frequencies. These are a fundamental of about $5.2 \mathrm{~Hz}$ with harmonics. On the $17 \mathrm{th}$ line the engine enters a non-recoverable stall (rotating stall); this frequency starts at $90 \mathrm{~Hz}$ and decays with engine speed. Electronic noise at 60,120 , and $180 \mathrm{~Hz}$ is also seen.

The separate occurrance of surge and rotating stall allows direct determination of $F_{x}$, that is the input filters, $G_{j}(s)$, in Fig. 4 are not required. This is quite important because some of the excursions in pressure and especially flow are very rapid. Presence of an input filter could soften this response to a point where the desired characteristic is masked, distorted, or becomes double valued.

Using a rationale presented in a later section, output and differentiator filters with 
corner frequencies of 200 and $400 \mathrm{~Hz}$, respectively were chosen.

Typical Characteristics

Effect of Compressor Speed

With the above filtering, compressor instantaneous force characteristics, $F_{X}$, were determined at several compressor corrected speeds in mode I (fig. 9(a)). If it is assumed that the stall cell build up lag, Fig. 2, is not required in this period, $\tau_{c}=0$, then these plots are the compressor surge characteristics which are to be determined. Because of the electrical and flow noise on the data the results are somewhat noisy, however, the basic form of the characteristic is readily discernable. As indicated above the force characteristic can be converted directly to the compressor pressure ratio versus corrected flow map (fig. 9(b)). It is also of interest to compare the simple (dynamic) pressure ratio normally seen to these results. These plots are shown in Fig. $g(c)$ for the identical surge cycles.

Parametric studies made with various values for ${ }^{\top} C$ during the surge instability did not show improvements in $F_{m}$ relative to $F_{X}$. That is, accounting for the lag dynamics did not either reduce the "flow" noise on the characteristic or make the value of $F$ during increasing and decreasing flow traverses coalesce better.

If the instantaneous force characteristics (as presented in fig. $9(\mathrm{a})$ ) are individually smoothed then a generalized force characteristic (force compressor map) may be formed, as shown in Fig. 10. Included on this figure for completeness is a characteristic determined during a mode II instability, the 92 percent speed line. This characteristic (fig. 11), (cycles 1 to 3 ) is somewhat different from those of Fig. 9(a). This is attributed to the rapid speed change during this time period.

Comparisons between adjacent mode I and mode II type instabilities, further into the run (when the speed is changing slowly), showed only small differences in the force characteristics. For $N_{C}=88 \Delta$ speed, stable side data points converted from a normally measured compressor map using Eq. (11) are superimposed on the data of Fig. 10. It can be seen that the shapes of the stable side characteristics are the same and that the post-stall characteristic leaves from a region of high performance and force (hence pressure ratio) and decreases as flow approaches zero. A local minimum in the characteristic occurs near zero flow and as negative flow increases the force characteristic also increases. The shape of the characteristics is guite different from those seen in the literature. (2) The post stall (positive flow) characteristic levels appear to be higher than those seen in the literature.

A typical characteristic plot $F_{x}$ vs $\dot{W}_{c}$, corr is shown in Figs. $12(a)$ and $12(b)$. It is annotated with letters $A$ through $G$ which mark particular events in the cycle. In Fig. 12(c), a set of typical variables involved in the characteristic determination are plotted against time. From the corresponding letter annotation it can be seen that the traverse from $A$ to $C$ (initial stall) and from $D$ to $F$ occur in a very short time relative to the period of one cycle of mode $I$.
Typically, $t_{A \rightarrow C}$ is about 3.4 percent of the mode I period and $t_{D \rightarrow F}$ is about 2.7 percent. These percentages will about double for a mode II instability. It is the rapid changes in

$\dot{W}_{c}$ that create a substantial $w_{C}$ term. This term then corrects the steady terms in the momentum equation (eq. (8)) to give the shape of the characteristic. For the same time period in the transient plots of $P_{3 T} / P_{2 T}$ versus corrected flow and $\left(P_{3 T} / P_{2 T}\right)$ CHAR versus corrected flow are presented in Figs. 12(d) and 12(e) respectively. The essential difference between Figs. $12(d)$ and $(e)$ is that $\left(P_{3 T} / P_{2 T}\right)$ CHAR accounts for the $W$ term.

\section{Additional Studies}

In order to examine the asumption of uniform flow over the length of the compressor, that is to determine the necessity of a spatial integration of the flow (eq. (2)), use of the flow at station 3 was investigated. In the above study the flow total pressure transducers were located near the midspan position at stations 2 and 3 . A second analog tape was created on which hub transducers were used at station 2 and a forward-reverse flow measurement at station 3 was implied by calibrating total and static pressure measurements in both forward and reverse flow.

Anomalous results were found for toth of these cases. The hub instruments appeared to indicate strong secondary flows and could not be used. Attempts to use a station 3 flow were not successful. The situation was further complicated by the fact that the total pressure was measured at a different circumferential location than the static pressure and amplitude and small phase differences were known to exist. Also, excessive instrument zero drift was seen.

Transition to Rotating Stall

of particular interest in this data is the period of transition from the surge (mode II) instability to rotating stall, which occurs about 32.5 seconds into the transient (fig. 13). Two methods were used to study this period of the transient. The first method was to use the standard filtering (output filter corner at $200 \mathrm{~Hz}$, differentiator filter corner at $400 \mathrm{~Hz}$ ) and to examine successive sections of the characteristic plot, Figs. 14(a) to (c), respectively. The figures show the last stall followed by an

increase in $\dot{W}_{c}$ corr but during this traverse $F_{x}$ does not increase back to the normal characteristic levels (fig. 14(a)). Several low force "loops" follow (fig. 14(b) and 14(c)) with the final rotating stall "average" (heavily filtered) performance point indicated on Fig. 14(c).

A second approach to examining the transition to rotating stall used progressively heavier filtering applied to the same transient. The period chosen began somewhat earlier (i.e., the 193rd cycle) and progressed into the rotating stall regime. The sequence shown in Figs. 15(a) to (c) applies successive filters each with one half the low pass corner frequency of the previous case. The force characteristic becomes distorted in shape and reduced in extent as the filtering is increased. Also, the characteristic becomes double valued as the filtering increases, as would 
be expected based on the results shown in the filtering section (below). The compressor speed does not change significantly over the period considered.

It is evident from these results that the "steady" rotating stall equilibrium point is separate and distinct from the Force (or Pressure) characteristics previously measured.

Specifically, the data appears to substantiate the existance of separate surge and rotating stall characteristics as hypothesized by Moore. (7).

Further study of Fig. 15(c) (and fig. 14) shows that the beginning of the transition starts from an area near the stable side of the surge characteristic (near a minimum $P_{3 T}$ and maximum $\dot{W}_{\text {corr }}$ ) and progresses to the left (reduced flow) and settles on the rotating stall characteristic. This is also seen from the variables plotted against time in Fig. 13, note beginning of rotating stall on $P_{2 T}$. Thus, it is conjectured that the combination surge-rotating stall characteristic has a form similar to that shown in Fig. 16. This form assumes some sort of a bifurcation point connecting the two characteristics. If this conjecture can be substantiated with additional data, the the important research question then becomes one of determining the physical (and hence mathematical) criterion which causes switching from one characteristic to the other. It is believed that this criterion will involve a relationship between the internal forces composing $F_{X}$. It is for this reason that the characteristics in this paper are presented as forces rather than pressure ratios. How the Grietzer B criterion $(2)$ fits into this picture is not clear but it is suspected that other issues which have not before been considered may be important. One such issue is the amplitude of the surge cycle, since if a bifurcation point does indeed exist switching from the surge characteristic to the rotating stall characteristic can only take place if the amplitude of the surge oscillation (on $F_{X}$ versus $\dot{W}_{C}$, corr map) reaches the bifurcation point.

Indeed, if this truly three-dimensional problem of compressor stability is to be grossly simplified into a two oscillator model, one for surge and one for rotating stall, two separate and distinct criteria may be required. That is, to explain those cases where rotating stall oscillations occur stably over part of the period of the surge cycles would require an on-off criteria for the rotating stall oscillator. While to cover the transition from surge to rotating stall (or reverse) would require a second criterion. Such conclusions, of course, can not be drawn on the basis of a single study and require consideration of dynamic data from many compressors.

Combining the rotating stall point (at $N_{C}=84$ percent) with the generalized surge force characteristic (at $N_{C}=84$ percent) yields the final combined characteristic map (fig. 17).

\section{Filtering}

Filtering is a crucial step in the determination of compressor characteristics from surge data. As mentioned above, filters are required to remove; flow and electrical noise, effects of rotating stall if present, and noise from the differentiation process. Because of the rapidity of certain parts of the surge transient (high frequency content) only very light filtering may be used. The particularly sensitive parts of the transient are rapid movements indicated on Fig. 12(b) from $A$ to $C$ and from $D$ to $F$. Referring to $F_{x}$ vs time (Fig. 12(c)), these segments appear as very short term transients, and are difficult to separate from background noise.

The basic philosophy. for selecting filter time constants (hence corner frequencies) was as follows. The filter was used with the lowest corner frequency which met the following criteria; (a) further increasing the corner frequency did not affect the $A$ to $B$ and $D$ to $F$ traverses in $F i g$. 12(b) materially, and (b) further decrease of the corner frequency would affect the basic shape of the characteristic or open the gap between the $A$ to $B$ and $D$ to $E$ traverses. This process was applied to the differentiator filter (for $F_{X}$ calculation) first, then to the output filters. Keeping the output filters in matched pairs appears to allow that corner frequency to be less than that of the differentiator filter. This resulted in corner frequencies of 400 and $200 \mathrm{~Hz}$ for the differentiator and output filters, respectively. The filter required for the differentiator used to calculate $F_{m}$, was set by allowing ${ }^{\tau_{c}}=0$, and increasing the filter corner frequency until $F_{m}$ vs $\dot{W}_{c, \text { corr }}$ approximated $F_{X}$ vs $\dot{W}_{c}$, corr. Then ${ }^{T} c$ was set to its desired (research) values. This yielded a corner frequency of $2400 \mathrm{~Hz}$.

The high corner frequencies chosen allowed a significant level of noise on the plotted results, however, this was felt to be justified to correctly identify underlying characteristic. The effects of moving the output and differentiator filter corner frequencies relative to the selected values is shown in Fig. 18. Reducing the corner frequencies tends to spread the rapid traverses indicated above making the characteristic appear to be double-valued. Increasing the corner frequency increases the noise without improving the definition of the underlying characteristic.

\section{Summary and Conclusions}

A technique for extracting the in-stall pumping characteristics for an axial flow compressor from engine surge data has been developed. The basic concept appears to be workable and is premised on uniform flow (time varying) over the compressor. The technique has been applied to a multi-stage compressor in a turbofan engine.

The manner in which the data are filtered has been found to be critical in the successful application of the method. The separate occurrance of 
surge and rotating stall in the data analyzed simplified the filtering problem, in as much as input filters were not required. Careful selection of the filters required for the approximate differentiations was also necessary. Excessive filtering was found to produce distorted and doublevalued surge characteristics. Insufficient filtering left excessive noise on the resulting characteristic.

Two instability modes were found in the data. These were a classical surge mode and a second instability at about half the surge frequency thought to be associated with the engine control. Characteristics determined from both modes, when compressor speed was near constant, were found to be indistinguishable.

Consideration of the transition from surge into rotating stall indicates the existence of separate surge and rotating stall characteristics. It appears that these characteristics meet at a bifurcation point located on the stable side of the surge characteristic.

The stall cell build-up lag dynamics were considered and were found not to improve (eliminate dynamics from) the surge characteristic. The 1 ag thus, may not to apply during the surge process. Accounting for the build-up lag did not yield improved results in the transition from surge to rotating stali.

Expressions are developed to allow further investigations into the nature of the components of the net compressor force. Use of these requires an estimate of the compressor frictional behavior.

Finally, the characteristics determined by the procedure are felt to be representative of the true characteristics. However, further refinements in the areas of instrumentation type, placement, quantity, noise, and drift levels an improved data acquisition and filtering technique should allow significant reduction of noise and improved definition of the characteristics and their interrelationship.
APPENOIX A

\section{ALTERNATE MOMENTUM EQUATION}

Rewriting Eq. (5) as:

$$
2\left(P_{Y}-P_{S}\right) A=p A V^{2}
$$

and substituting Eq. (Al) into Eq. (4) and solving for $F_{x}$ yields:

$$
\begin{aligned}
F_{x}=\left(2 P_{3 T}-P_{3 S}\right) A_{3}-\left(2 P_{2 T}\right. & \left.-P_{2 S}\right) A_{2} \\
& +\frac{\ell}{g} \frac{d \dot{W}_{c}}{d t}
\end{aligned}
$$

as an alternative for $\mathrm{Eq} .(8)$.

\section{References}

1. Wenze1, L. M. and Bruton, W. M., "Analytical Investigation of Nonrecoverable Stall," NASA TM-82792, 1982.

2. Greitzer, E. M., "Surge and Rotating Stall in Axial Flow Compressors. Part 1: Theoretical Compression System Model," Journal of Engineering for Power, vol. 98, No. 2, Apr. 1976, pp. 190-198.

3. Corbett, A. G. and Elder, R. L., "Mathematical Modelling of Compressor Stability in Steady and Unsteady Flow Conditions," Unsteady Phenomena in Turbomachinery, AGARD 177, Paper No. 12, Sept. 1975.

4. Willoh, R. G. and Seldner, K., "Multistage Compressor Simulation Applied to the Prediction of Axial Flow Instabilities," NASA TM X-1880, 1969.

5. Gamache, R. N.: Unpublished Paper - Forced Non-Recoverable Stall in Compression Systems, MIT, 1983.

6. Shapiro, A. H., The Dynamics and Thermodynamics of Compressible Fluid Flow, Vol. 1, Ronald Press Co., New York, 1953.

7. Moore, F. K., "A Theory of Rotating Stall of Multistage Axial Compressors," NASA CR-3685, 1983. 


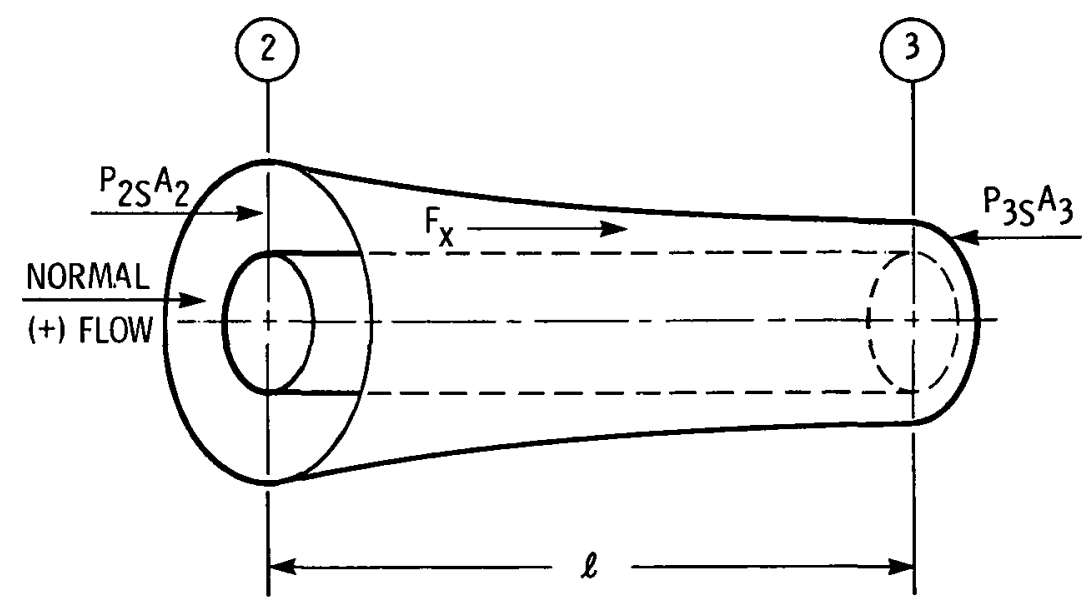

Fig. 1. - Forces on compressor fluid.

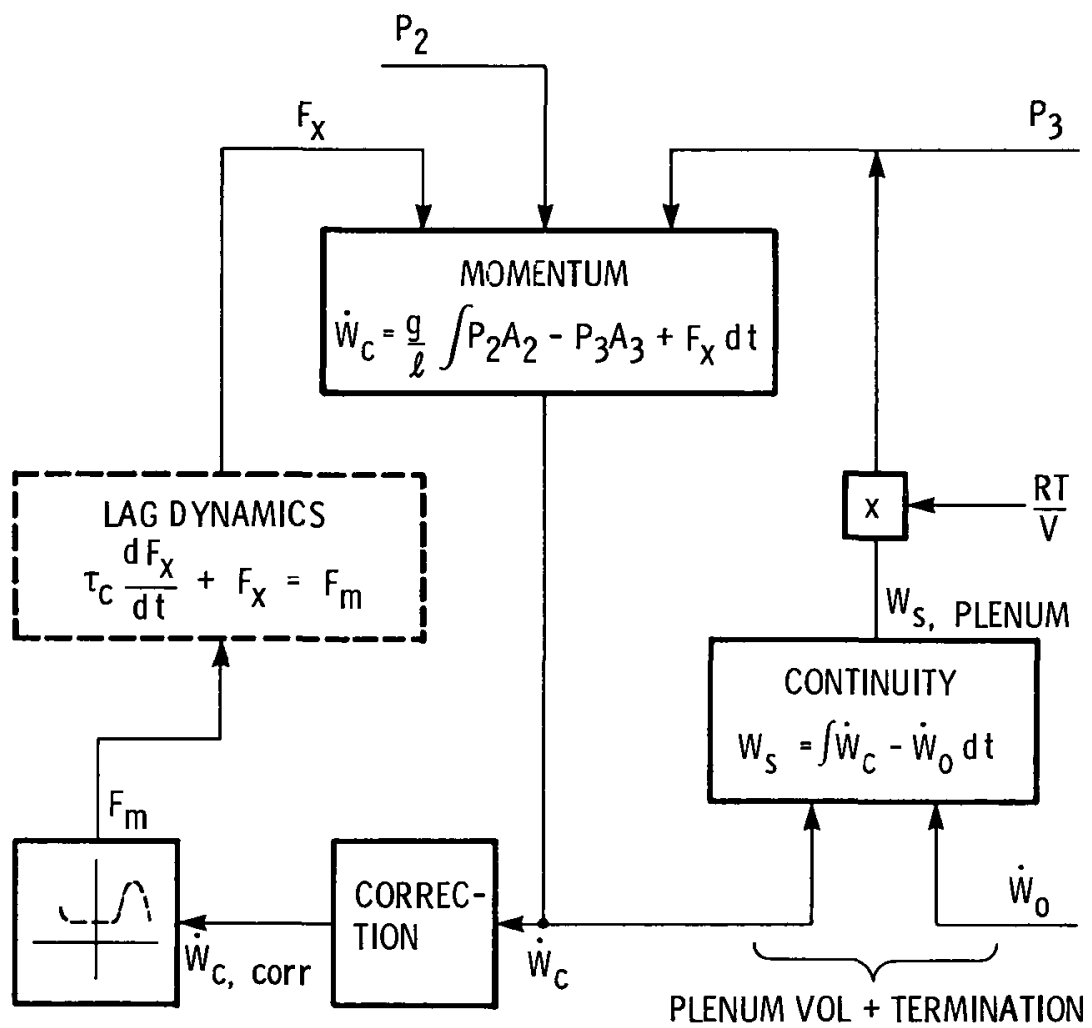

Fig. 2. - One dimensional surge model. 


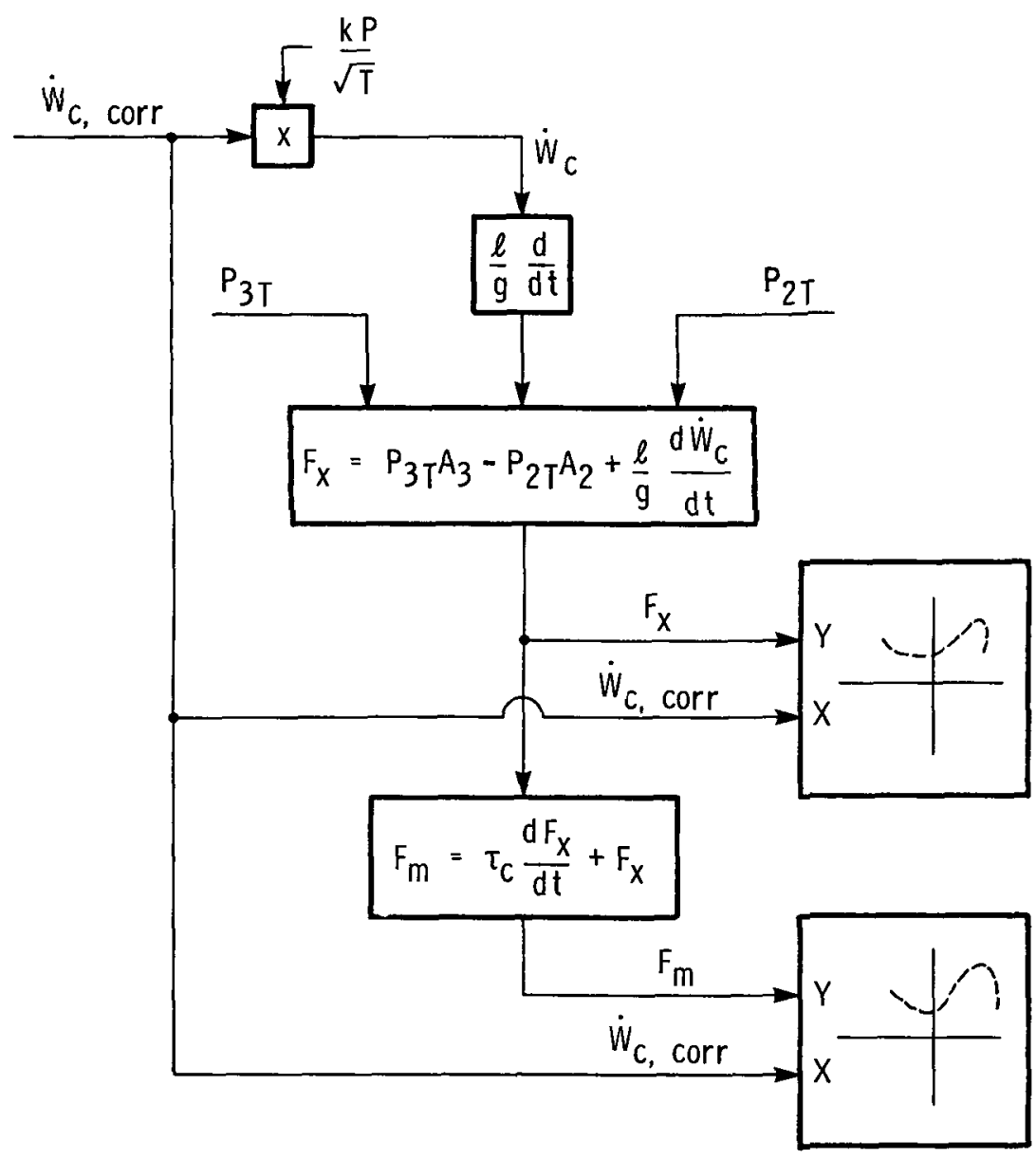

Fig. 3. - Simplified block diagram for determination of $F_{x}$ and $F_{m}$. 


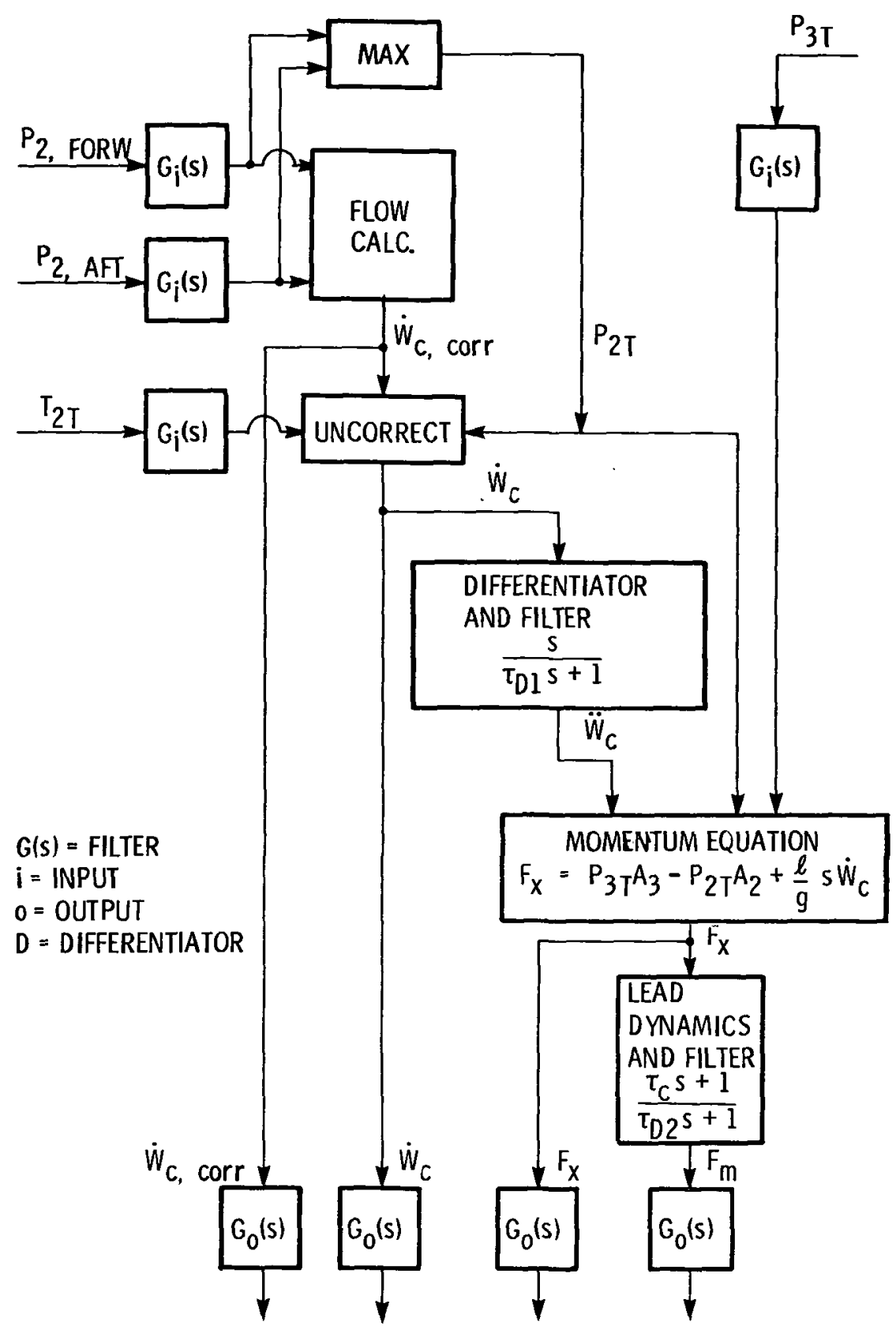

Fig. 4. - Block diagram for practical determination of forces $F_{x}$ and $F_{m}$.

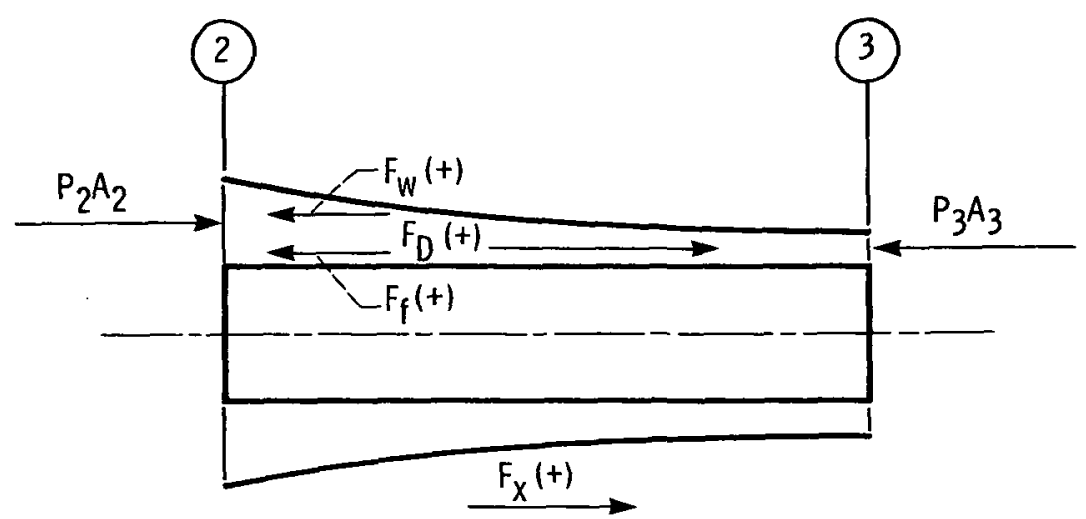

Fig. 5. - Instantaneous force components. 

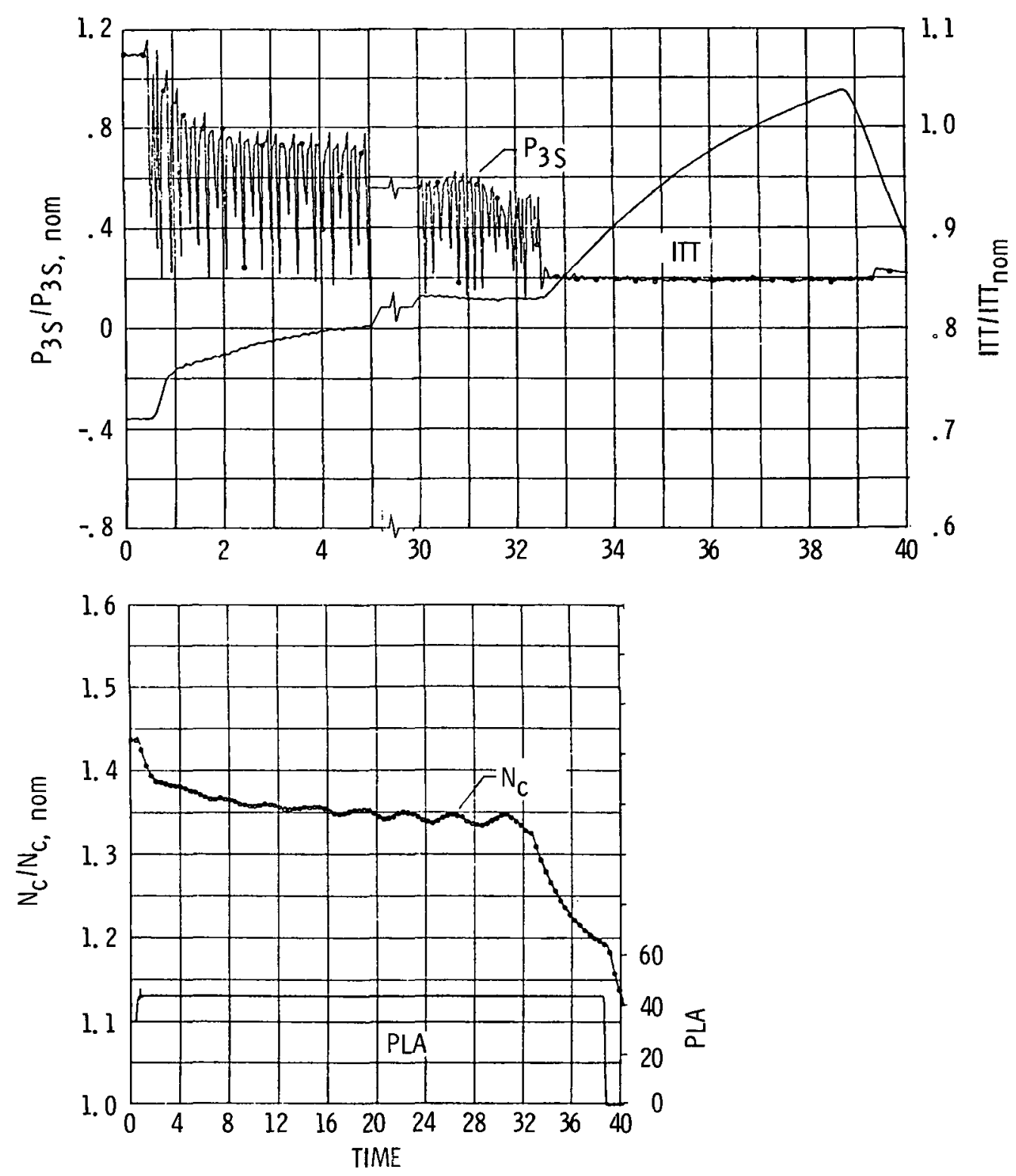

Fig. 6. - Nonrecoverable stall - transient. Fuel pulse at $92 \% \mathrm{~N}_{\mathrm{C}^{\circ}}$ 


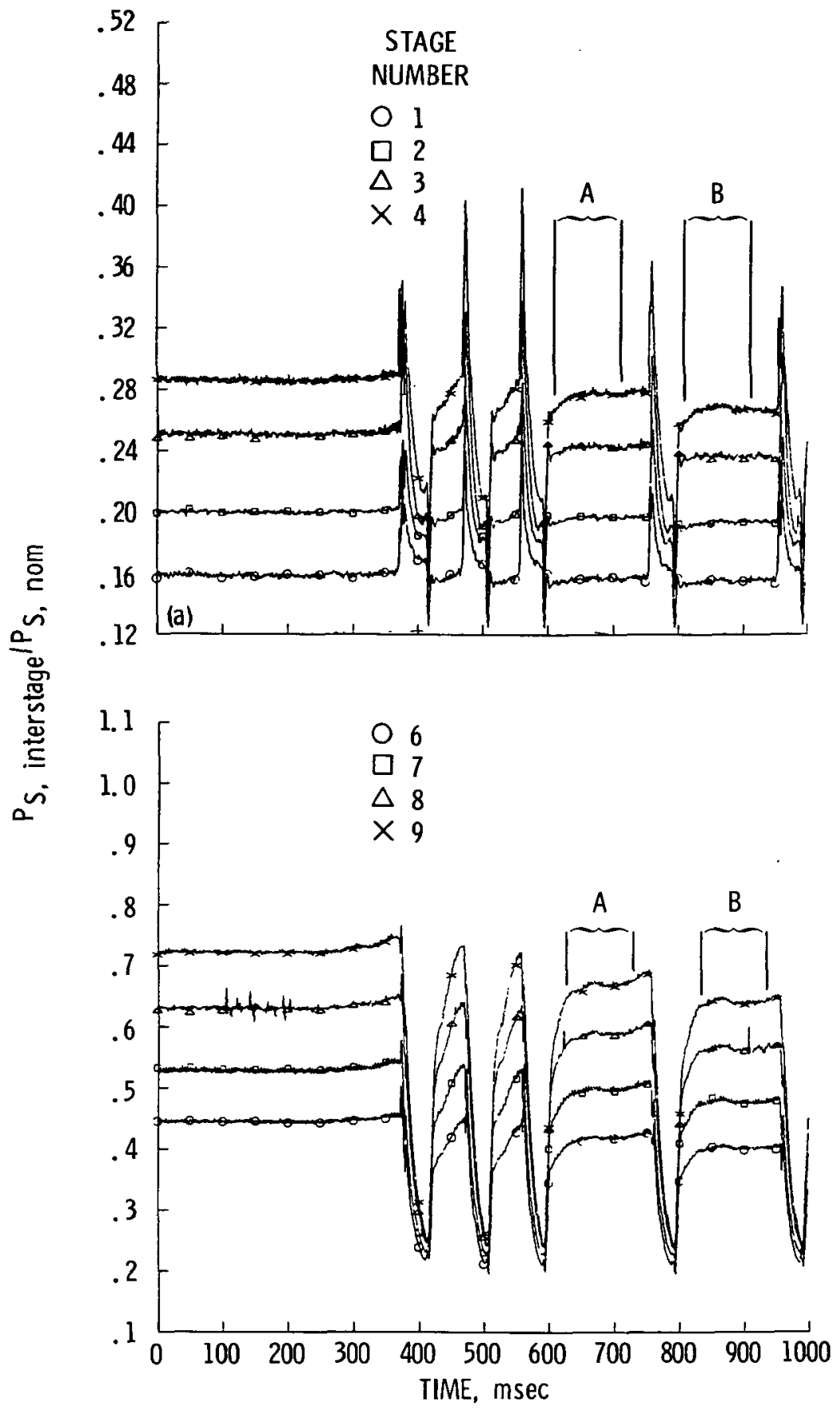

Fig. 7. - Interstage static pressures. 


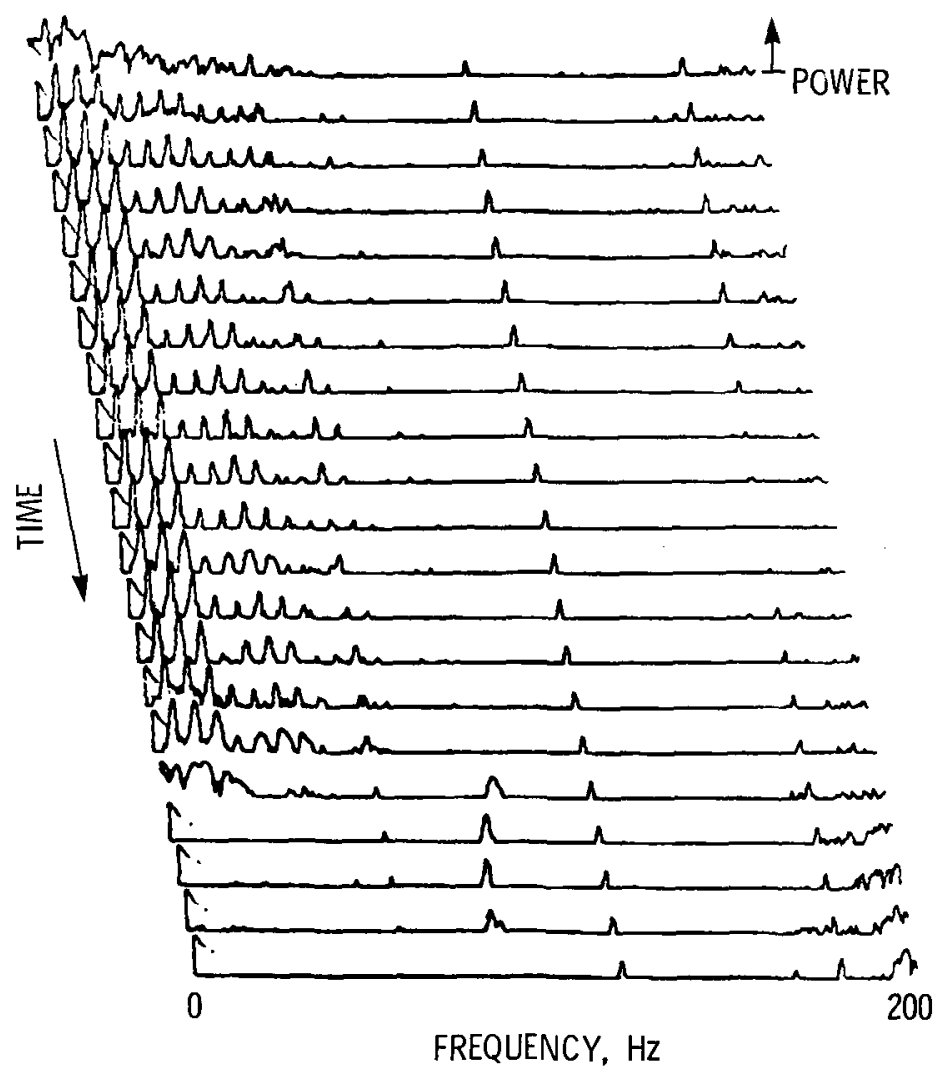

Fig. 8. - Power spectral analysis versus time of $P_{3 T}$ surge into rotating stall at $2 \mathrm{sec} / \mathrm{line}$. 

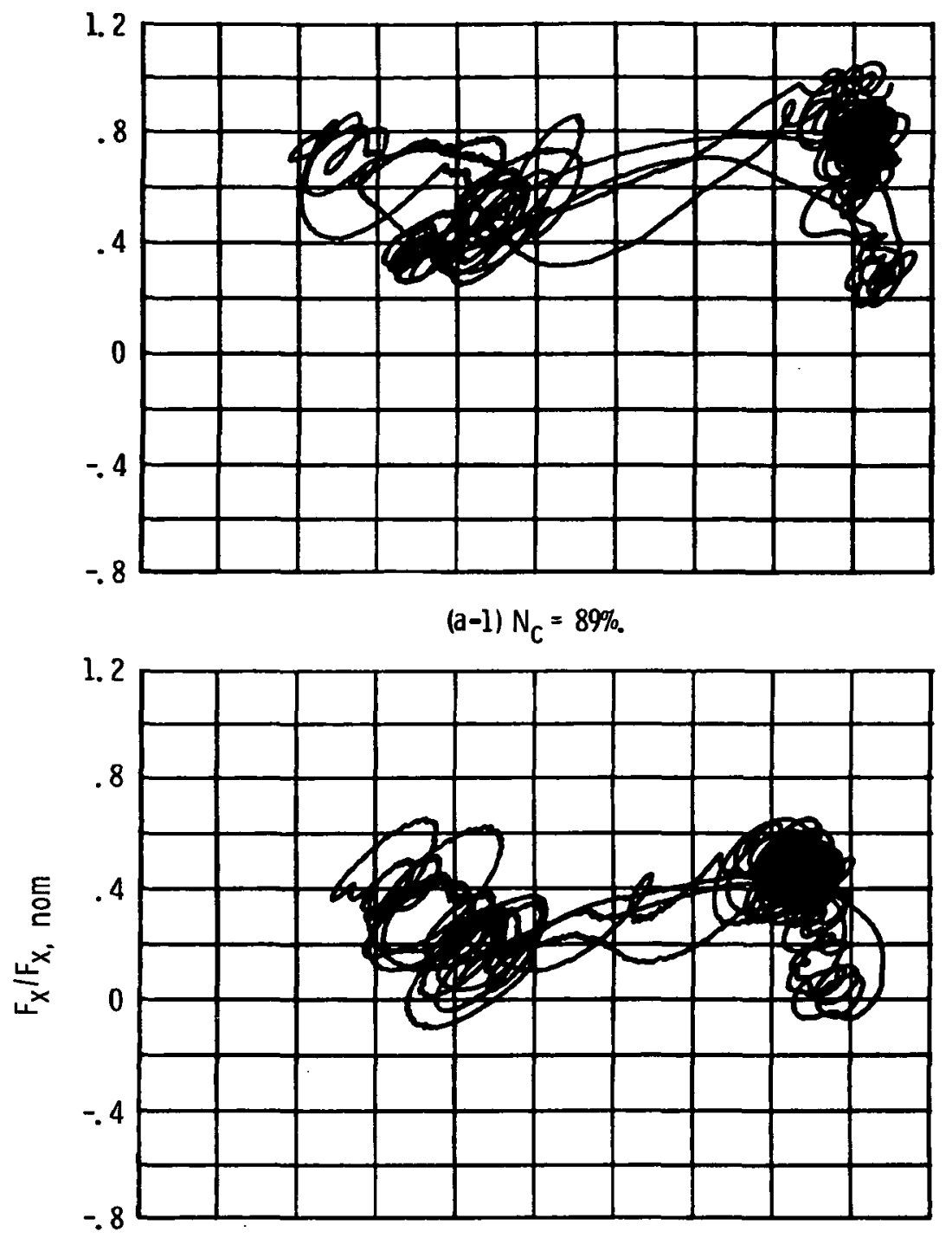

$(a-2) N_{C}=86.4 \%$.

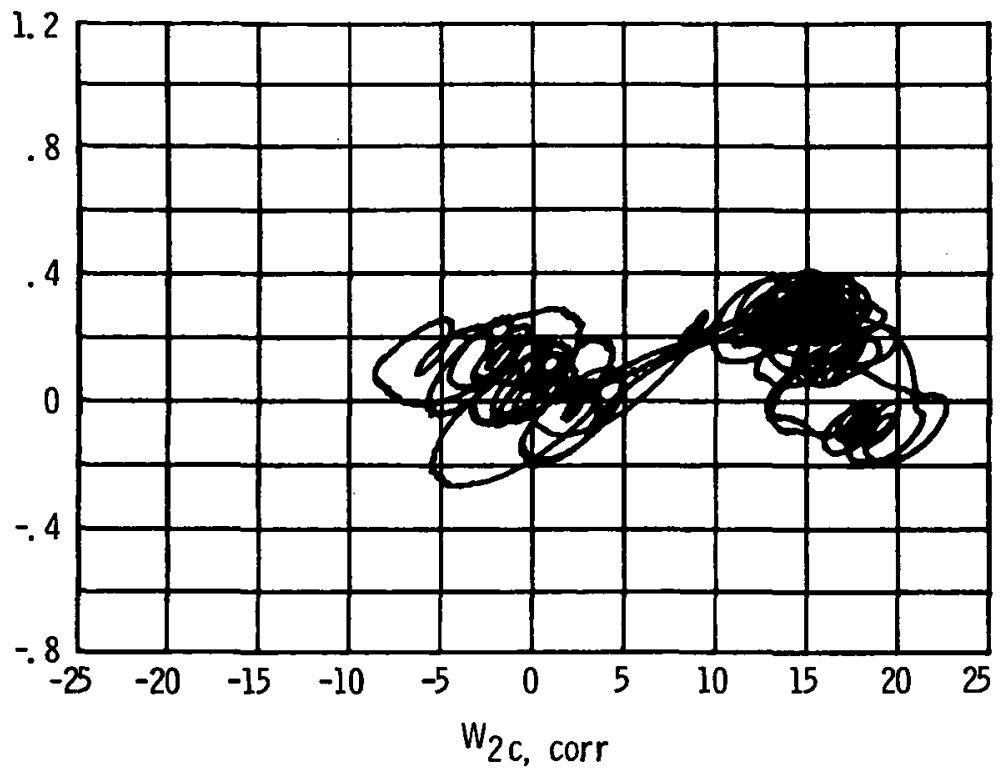

$(a-3) N_{C}=84.7 \%$.

(a) Compressor force characteristic.

Fig. 9. - Effect of compressor speed. $F_{0}=200 \mathrm{~Hz} ; F_{d}=400 \mathrm{~Hz}$. 

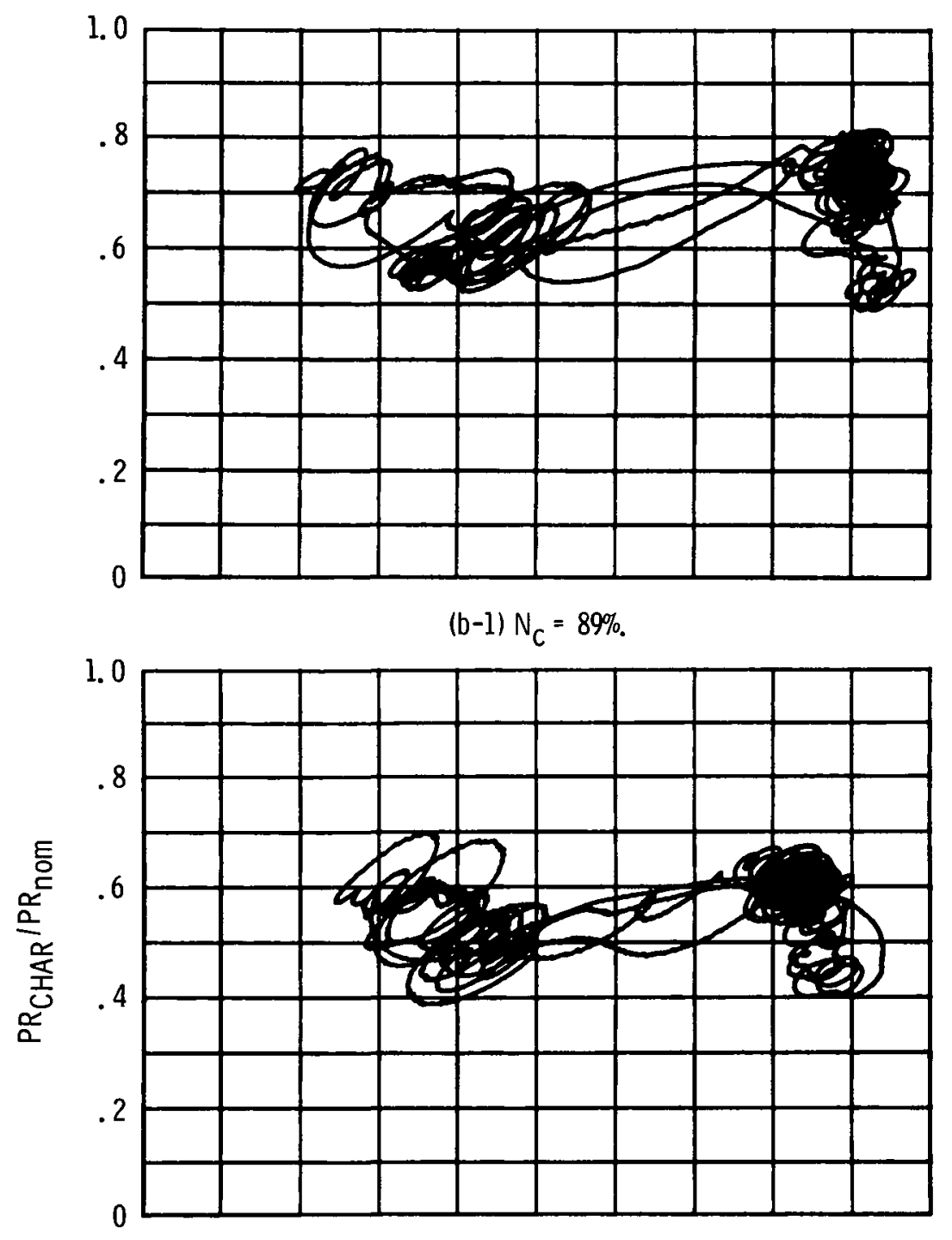

$(\mathrm{b}-2) \mathrm{N}_{\mathrm{C}}=86.4 \%$.

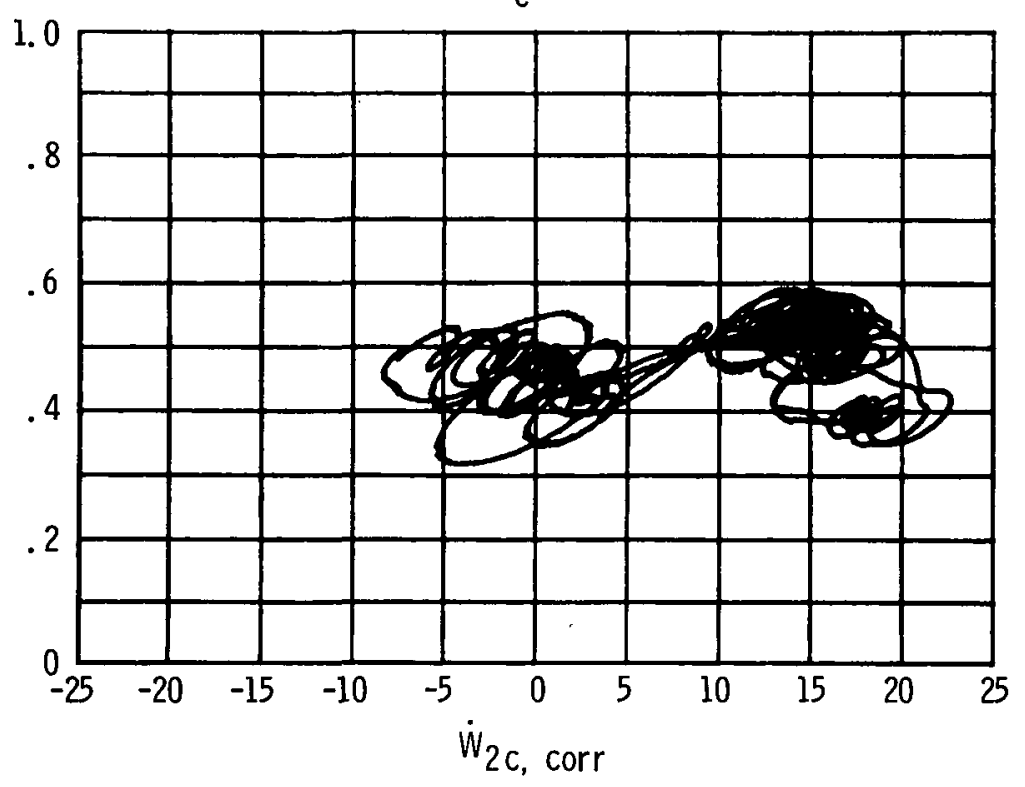

(b-3) $\mathrm{N}_{\mathrm{C}}=84.7 \%$.

(b) Compressor pressure ratio characteristics.

Fig. 9. - Continued. 


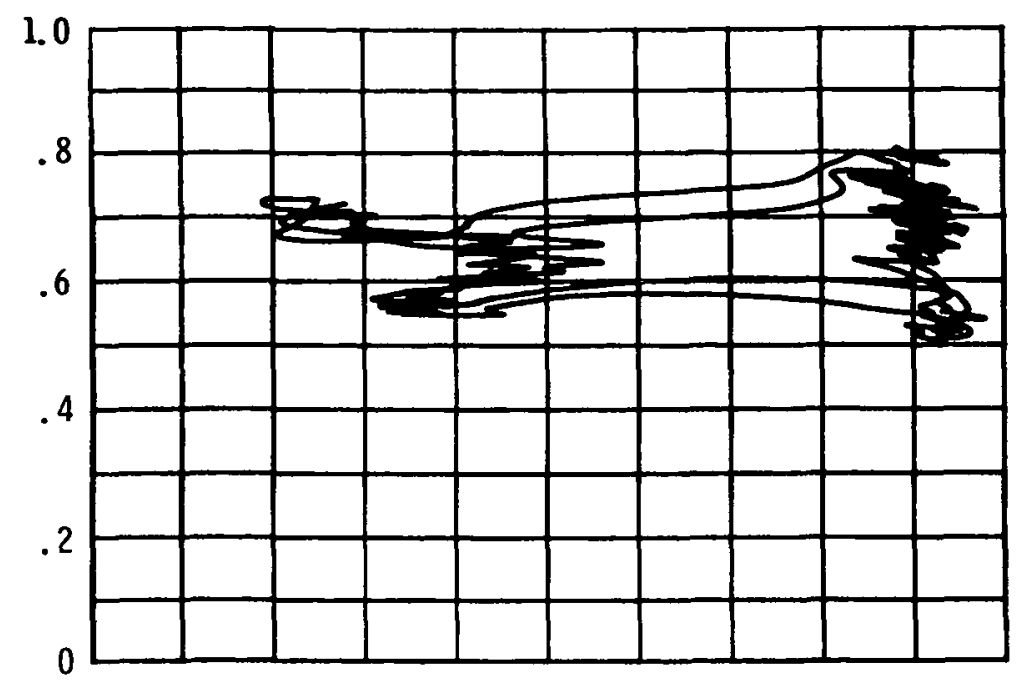

(c-1) $\mathrm{N}_{\mathrm{C}}=89 \%$.

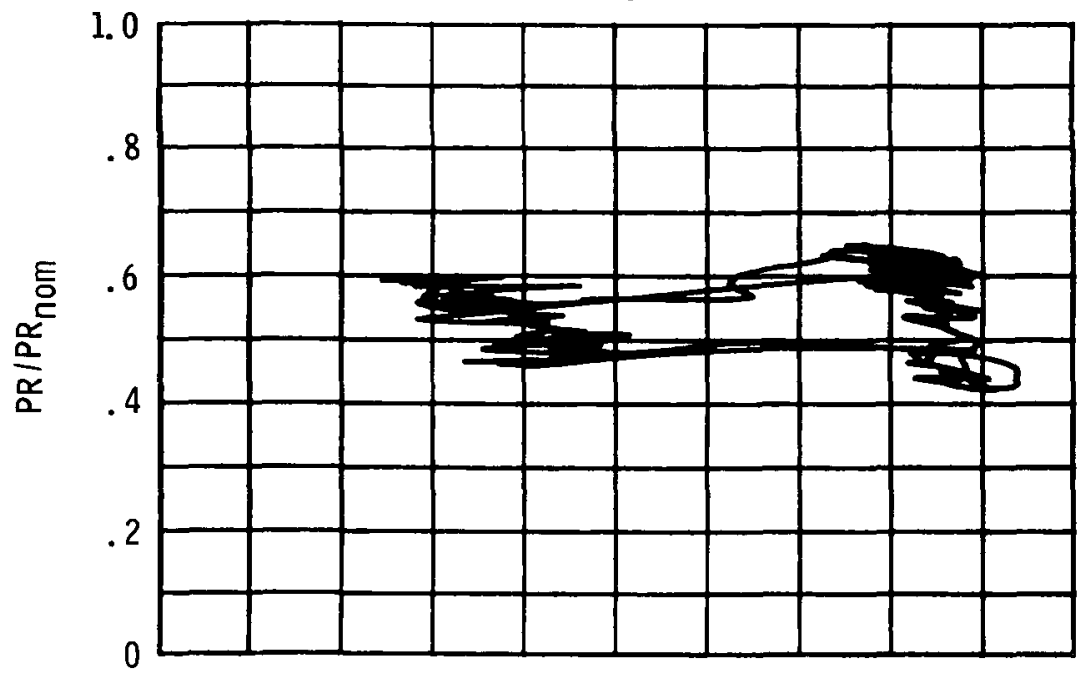

$(c-2) N_{C}=86.4 \%$.

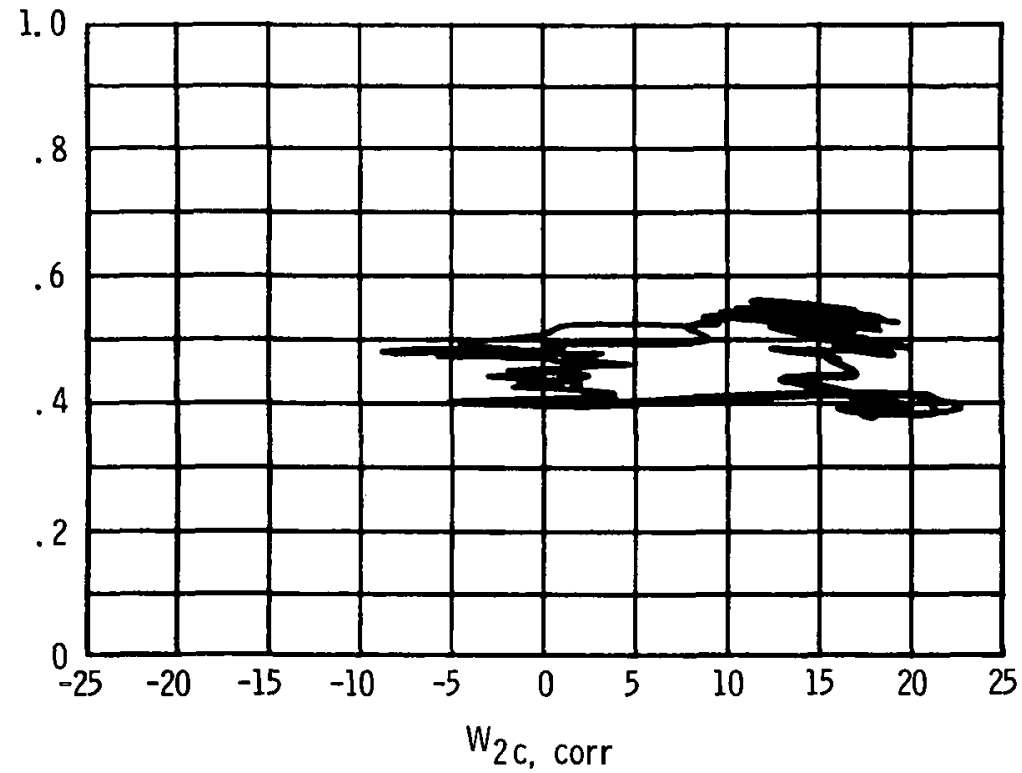

(c-3) $\mathrm{N}_{\mathrm{C}}=84.7 \%$.

(c) Compressor pressure ratios.

Fig. 9. - Concluded. 


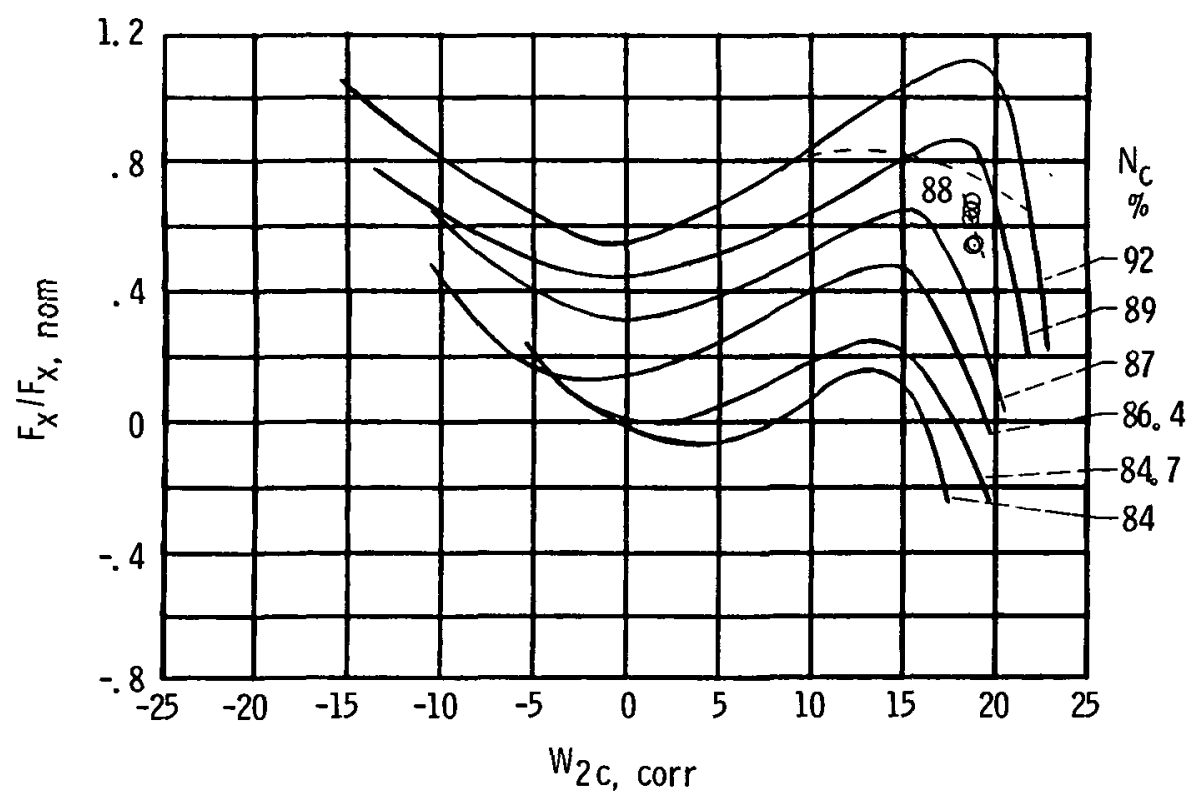

Fig. 10. - Compressor generalized force characteristic. $F_{0}=200 \mathrm{~Hz}$; $F_{d}=400 \mathrm{~Hz}$.

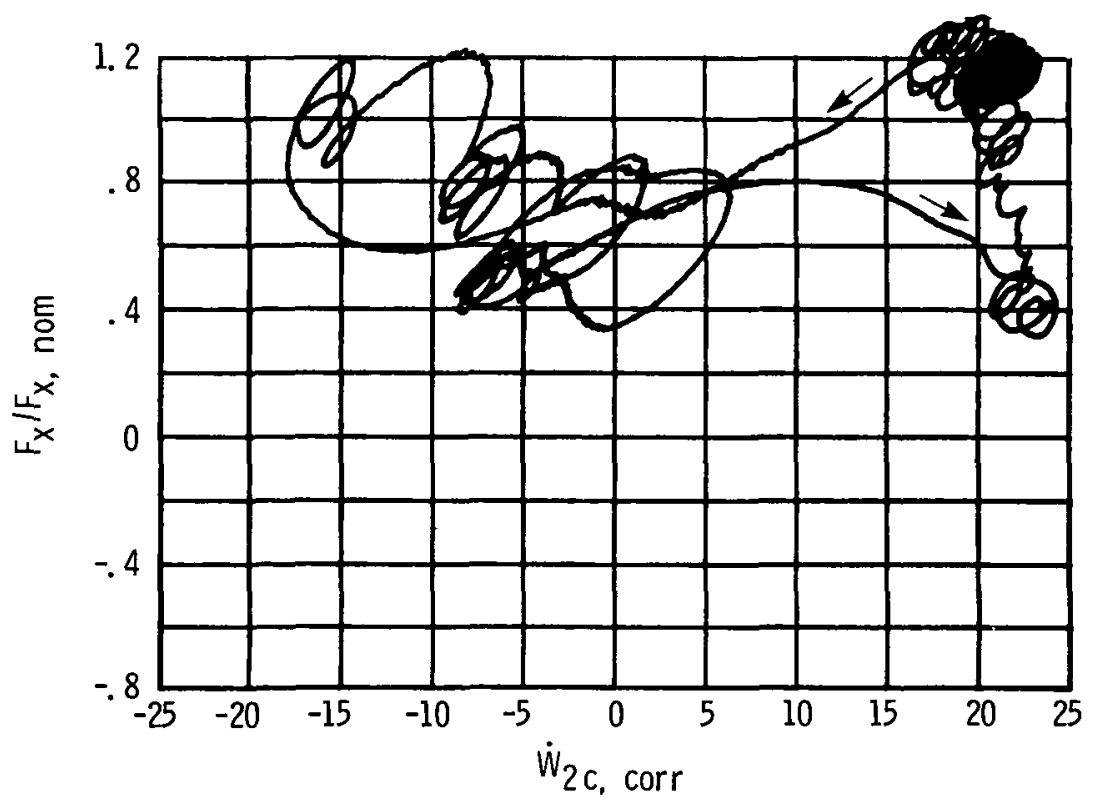

Fig. 11. - Force characteristic in mode II instability. $N_{C}=92 \%$; $F_{0}=200 \mathrm{~Hz} ; F_{d}=400 \mathrm{~Hz}$. 


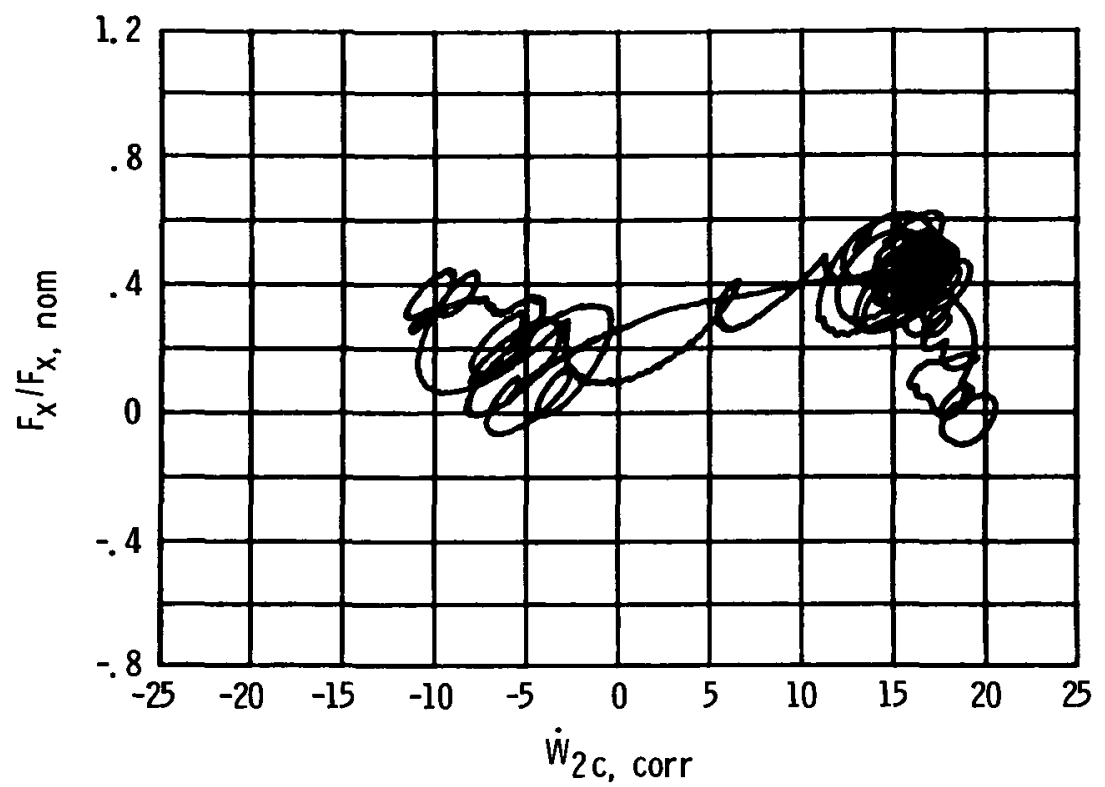

(a) Force characteristic.

Fig. 12. - Typical transient. $N_{C}=86.4 \% ; F_{0}=200 \mathrm{~Hz} ; F_{d}=400 \mathrm{~Hz}$; cycle 22.

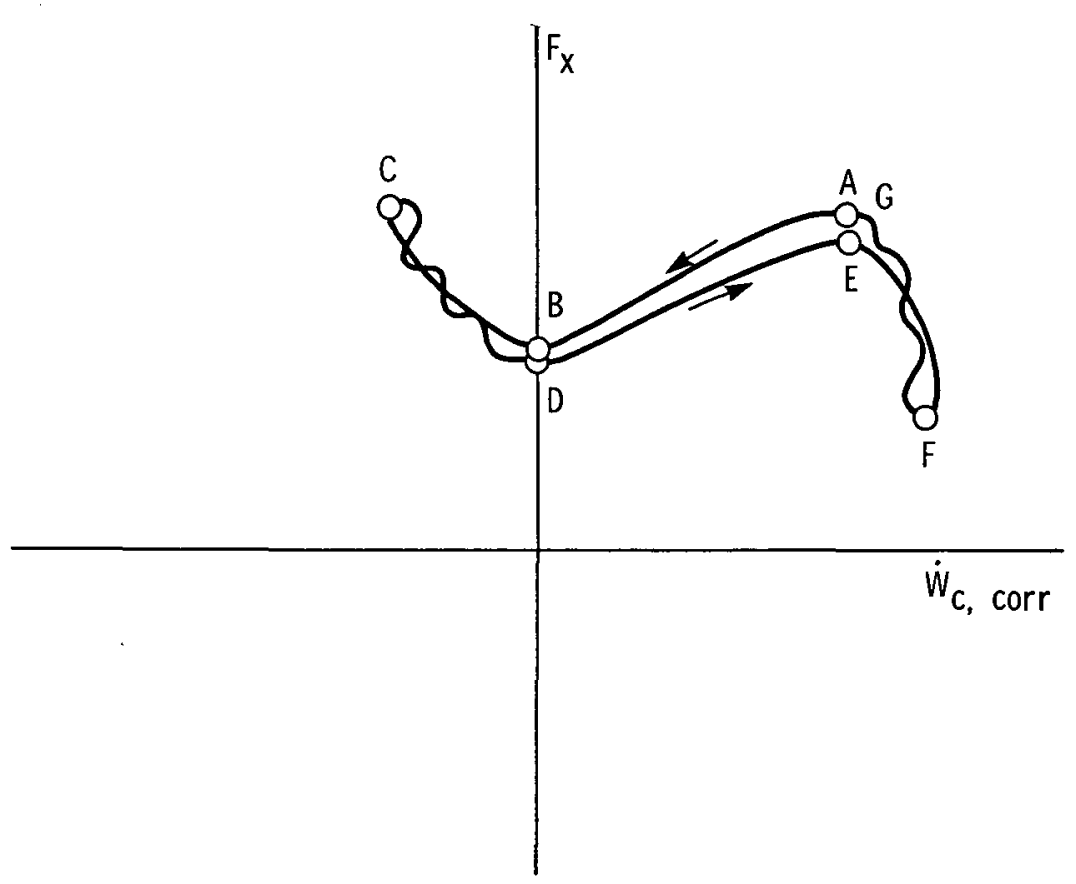

(b) Annotated force characteristic.

Fig. 12. - Continued. 

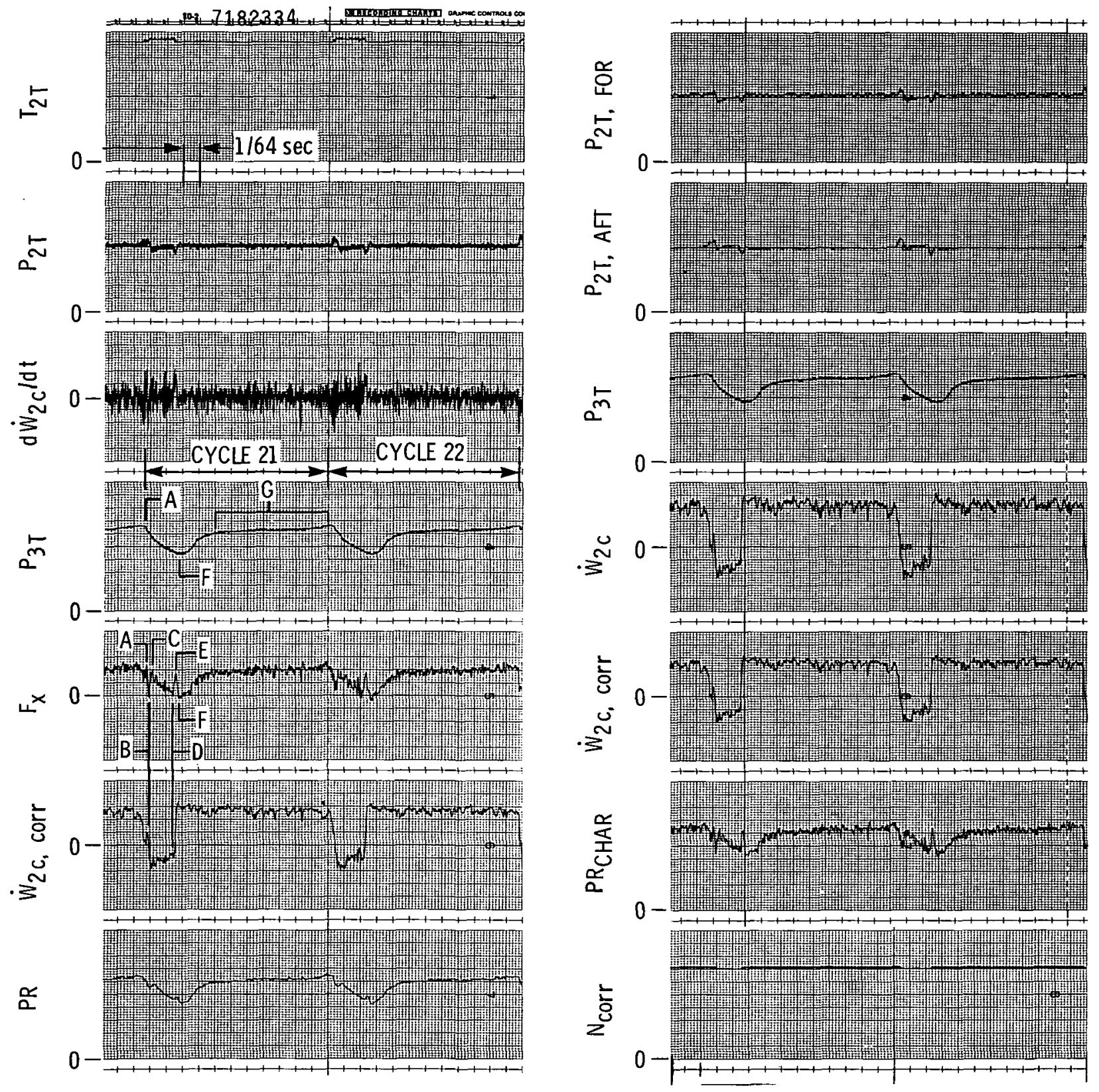

(c) Time.

Fig. 12. - Continued. 


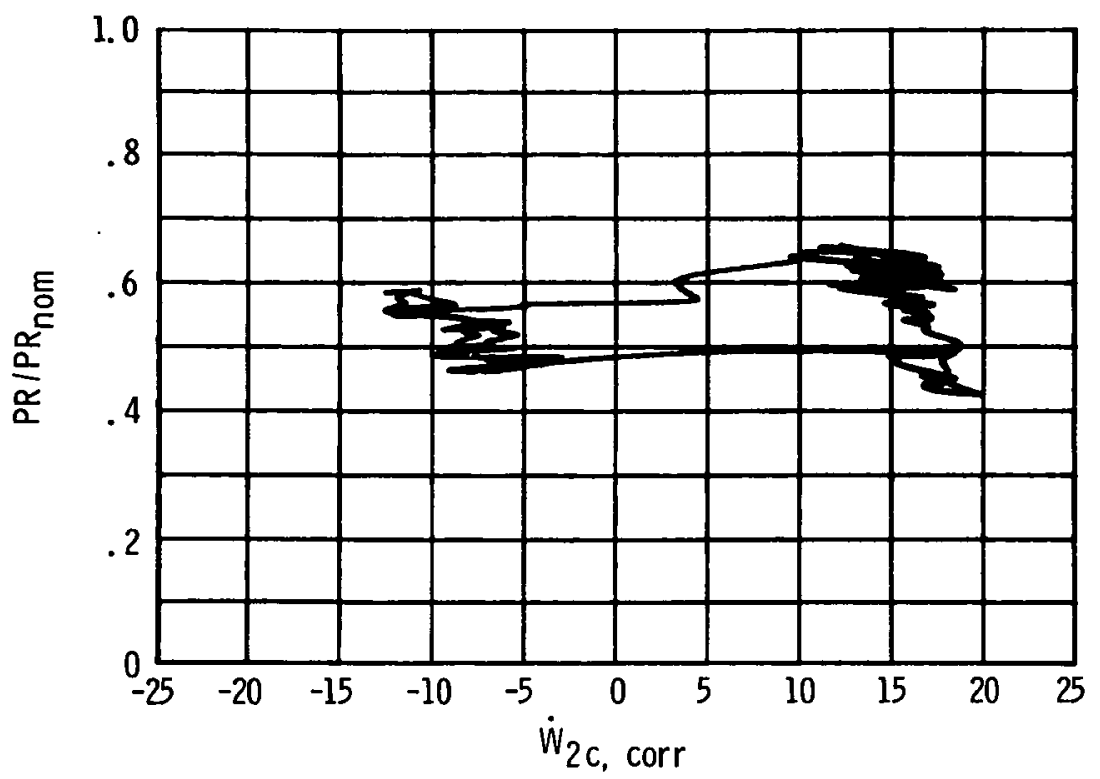

(d) Pressure ratio.

Fig. 12. - Continued.

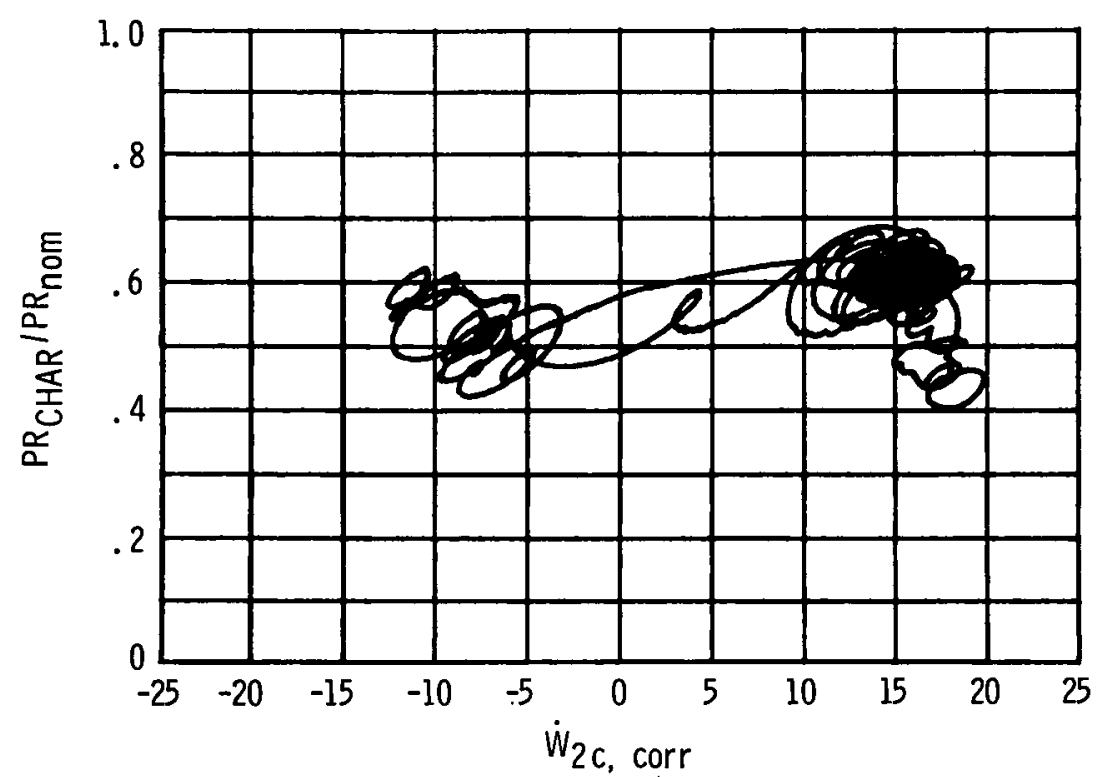

(e) Pressure ratio characteristic.

Fig. 12. - Concluded. 

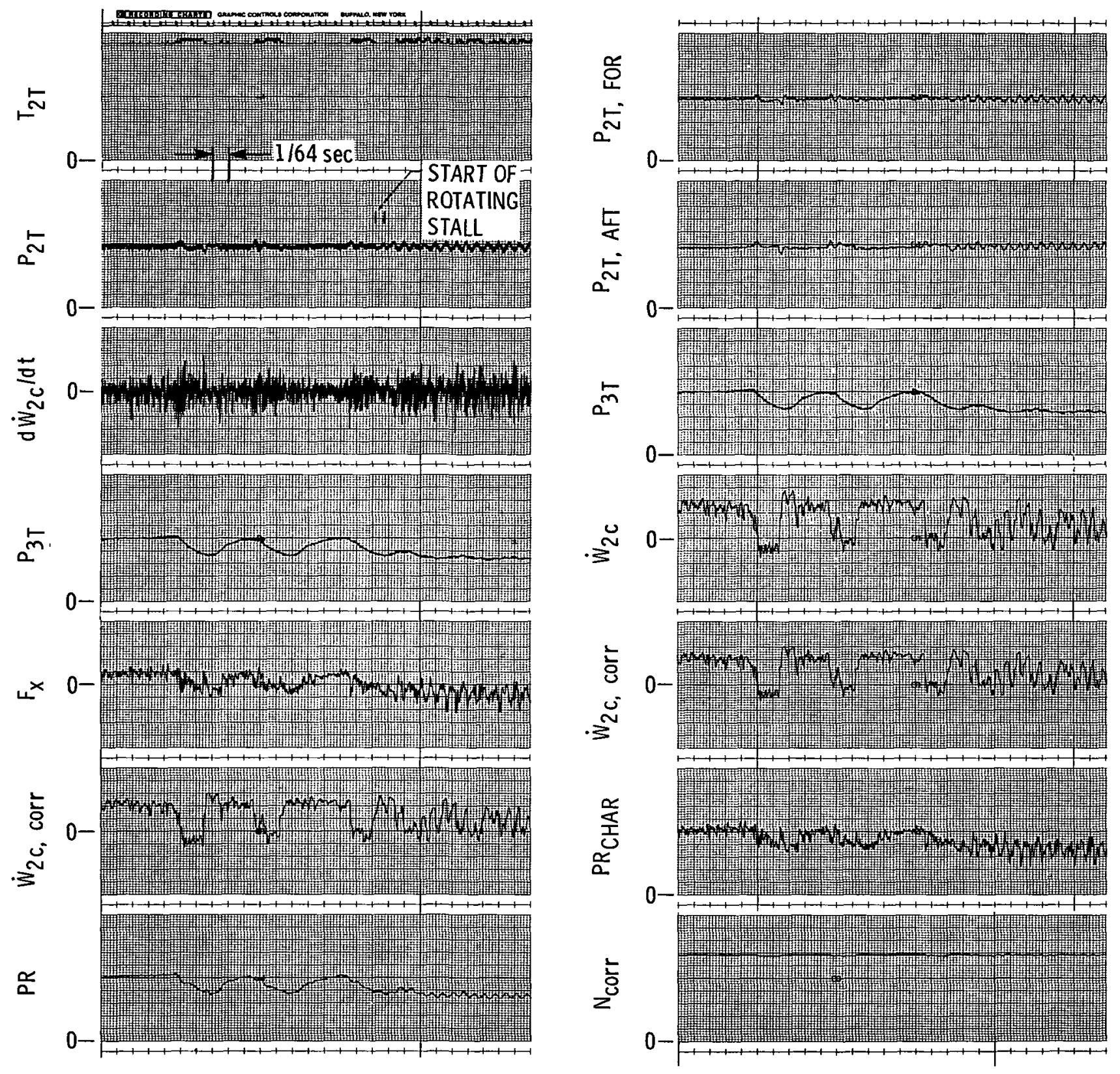

Fig. 13. - Transition to rotating stall - time transients. 


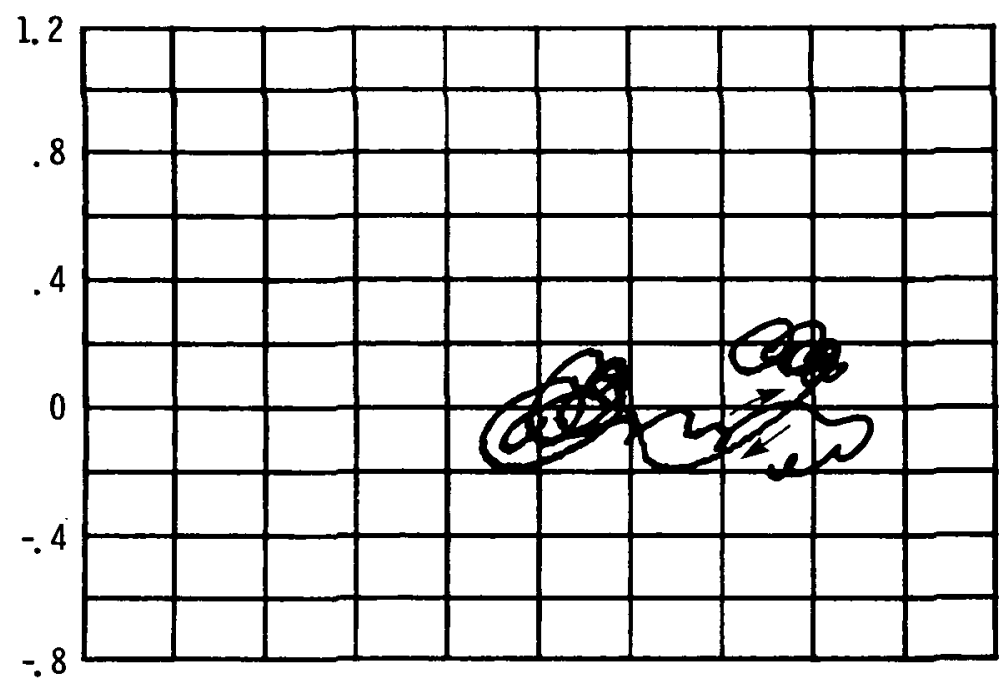

(a) Time segment 1 .

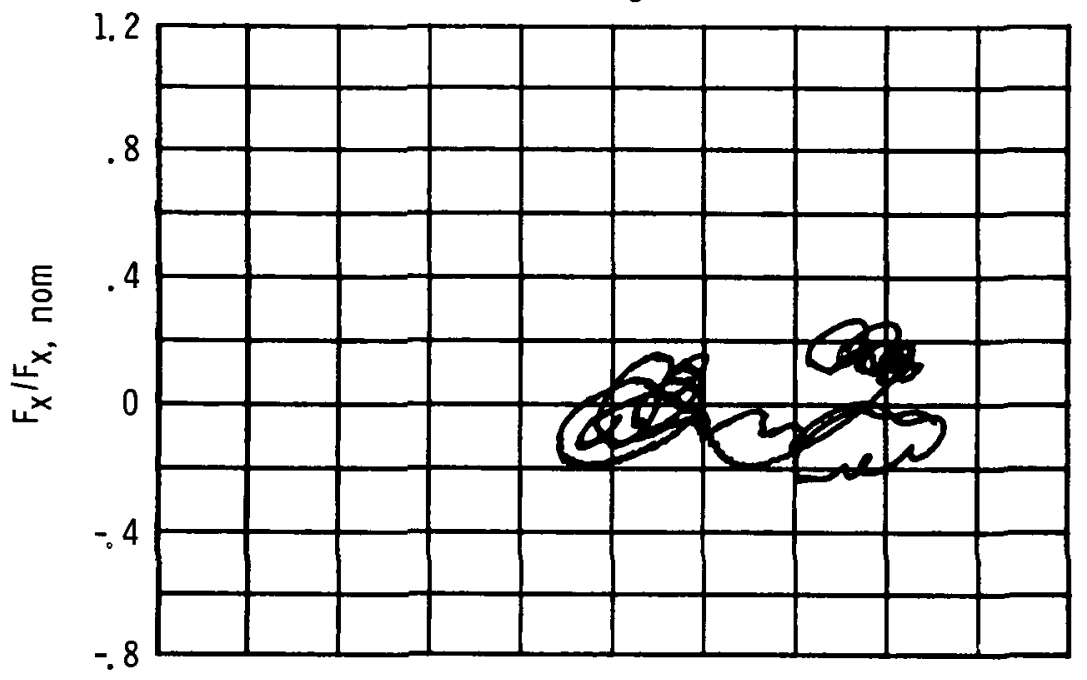

(b) Time segment 2

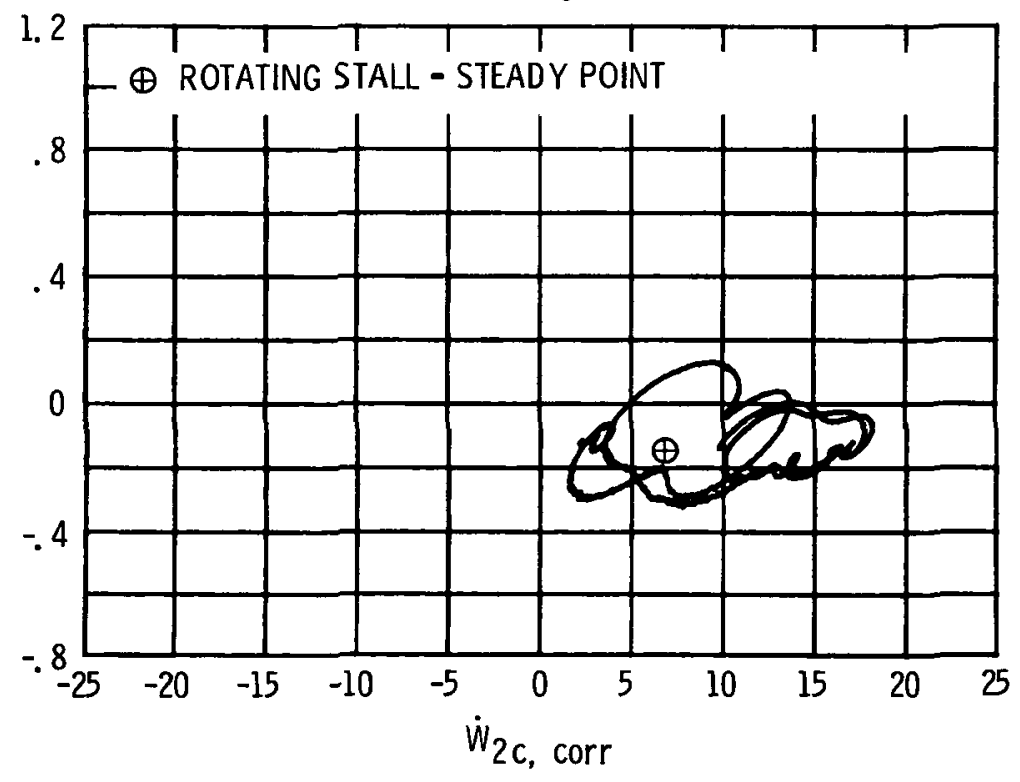

(c) Time segment 3.

Fig. 14 - Transition to rotating stall - progressive time segments. $\mathrm{N}_{\mathrm{C}}=84 \% ; \mathrm{F}_{0}=200 \mathrm{~Hz} ; \mathrm{F}_{d}=400 \mathrm{~Hz}$. 


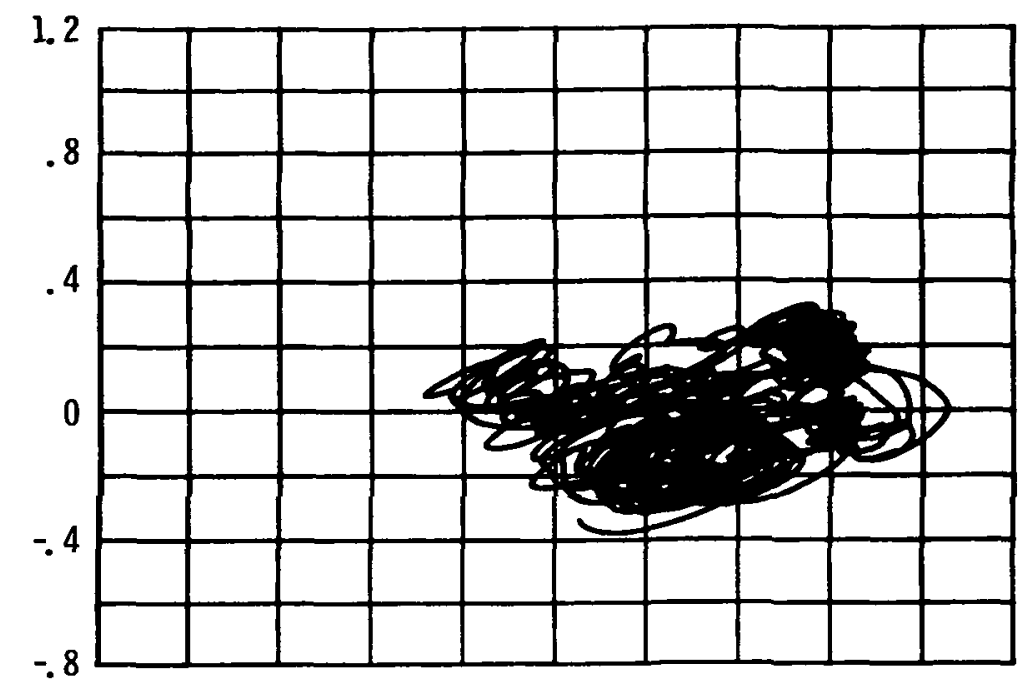

(a) $F_{0}=100 \mathrm{~Hz} ; F_{d}=200 \mathrm{~Hz}$.

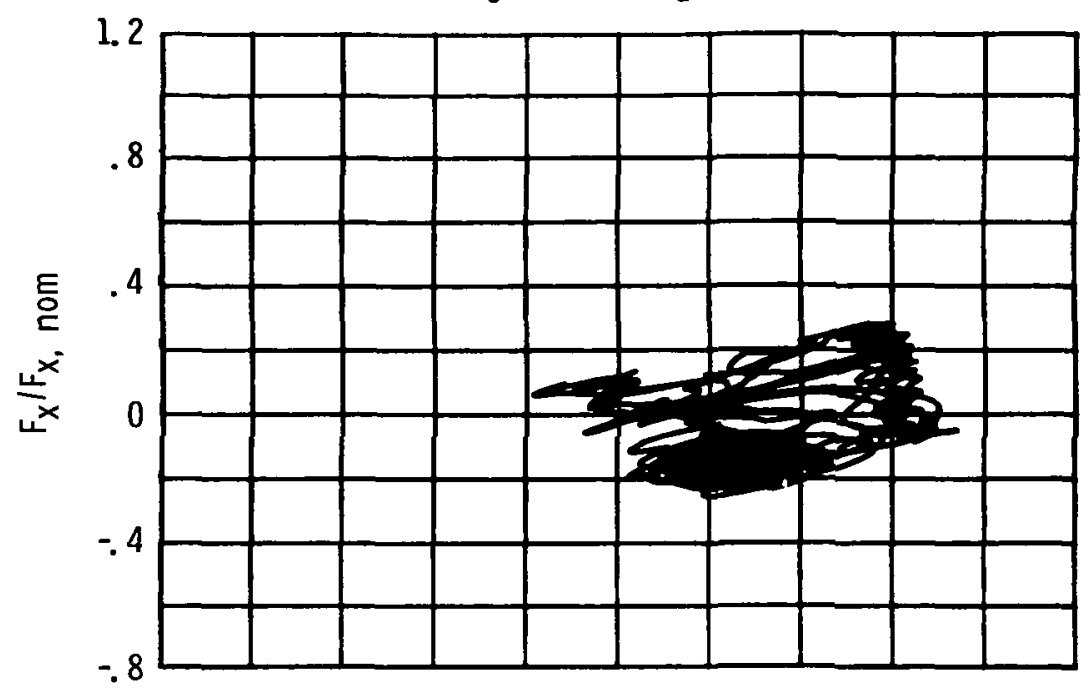

(b) $F_{0}=50 \mathrm{~Hz} ; F_{d}=100 \mathrm{~Hz}$.

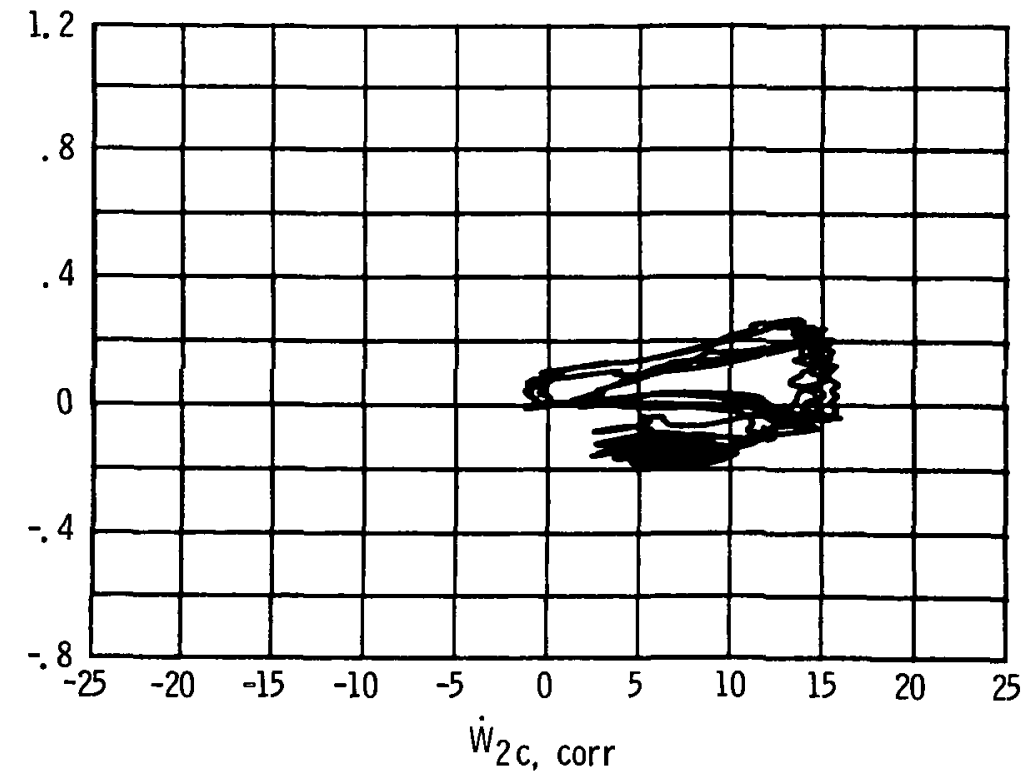

(c) $F_{0}=25 \mathrm{~Hz} ; F_{d}=50 \mathrm{~Hz}$.

Fig. 15. - Transition to rotating stall - progressive filtering, $\mathrm{N}_{\mathrm{C}}=84 \%$. 


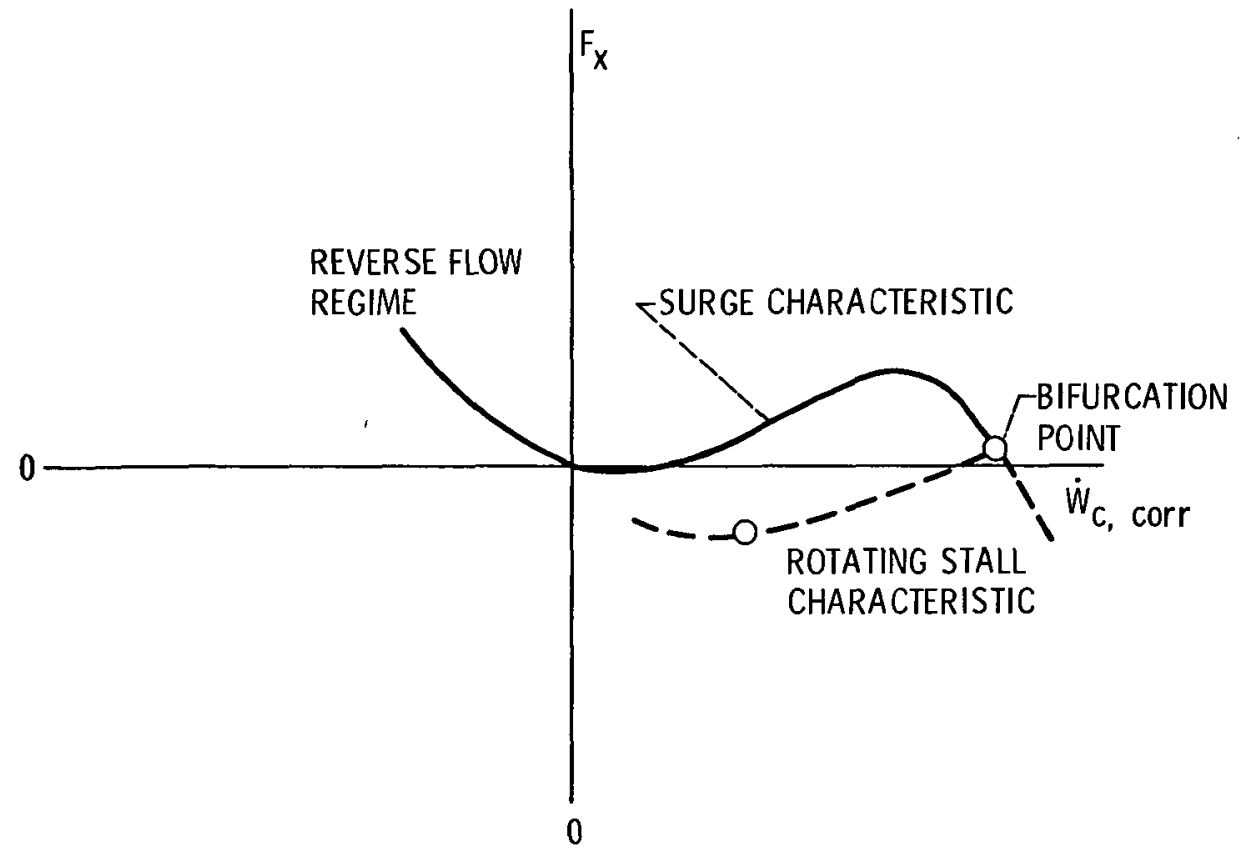

Fig. 16. - Combined surge - rotating stall characteristic.

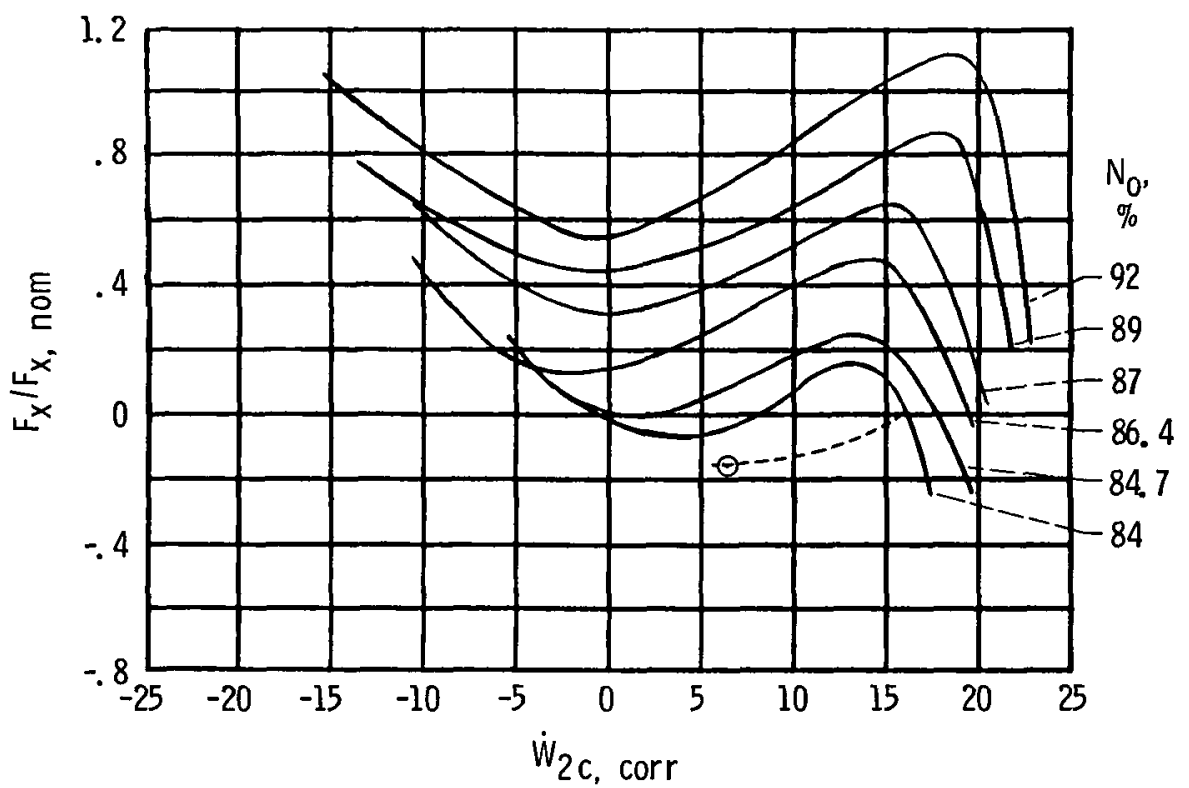

Fig. 17. - Compressor generalized force characteristic. $F_{0}=200 \mathrm{~Hz}$; $F_{d}=400 \mathrm{~Hz}$. 


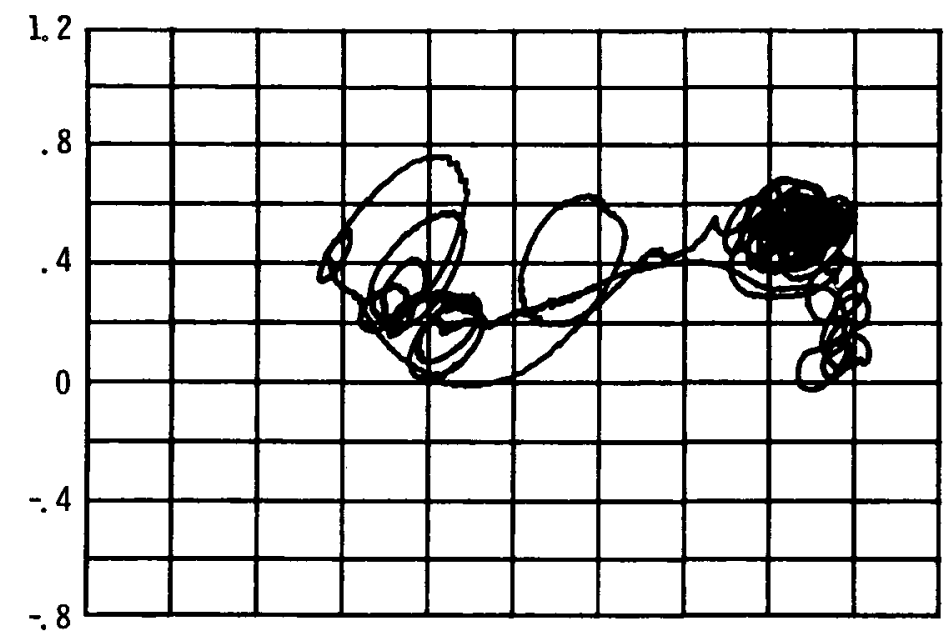

(a) Increasing differentiator filter corner frequency; $F_{0}=$ $200 \mathrm{~Hz} ; F_{d}=600 \mathrm{~Hz}$.

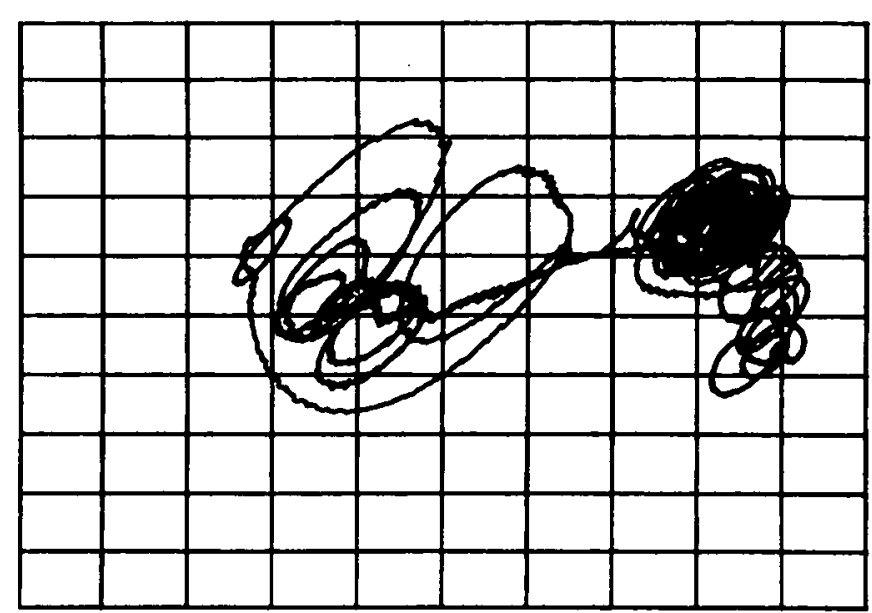

(b) Increasing output filter corner frequencies; $F_{0}=400 \mathrm{~Hz}$; $F_{d}=400 \mathrm{~Hz}$.

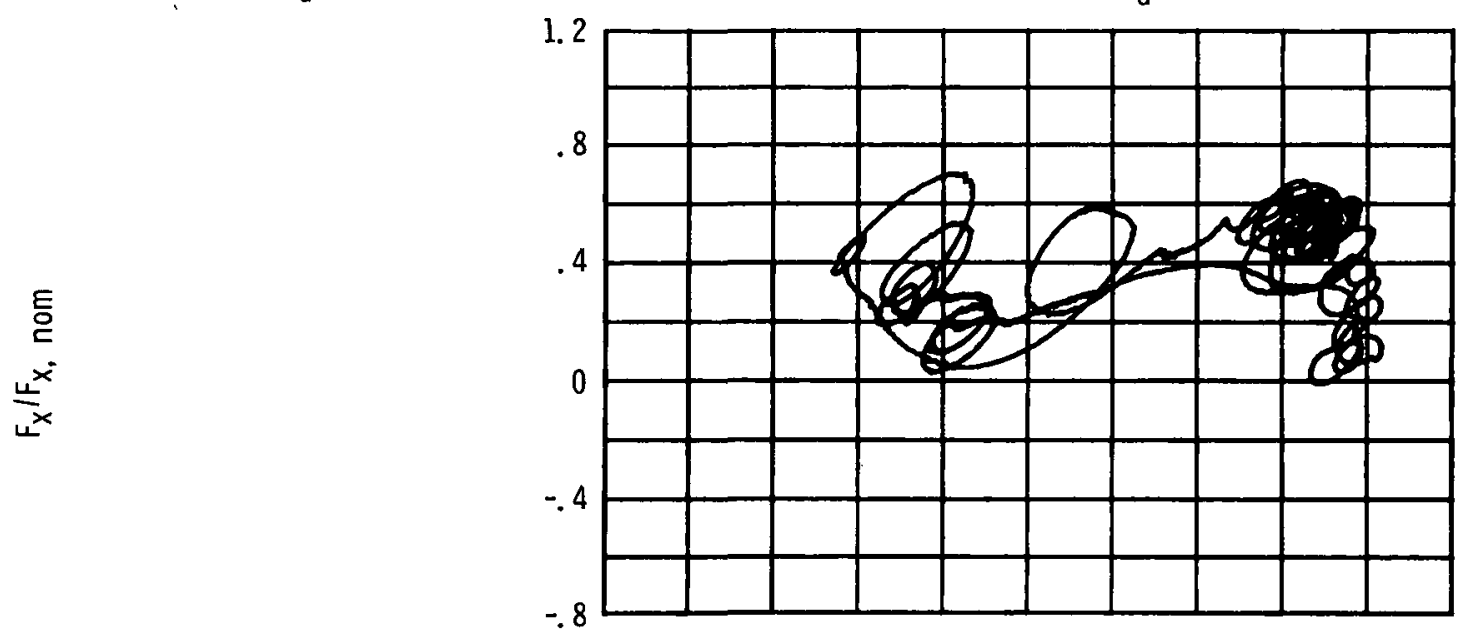

(c) Nominal filtering; $F_{0}=200 \mathrm{~Hz} ; F_{d}=400 \mathrm{~Hz}$ 。

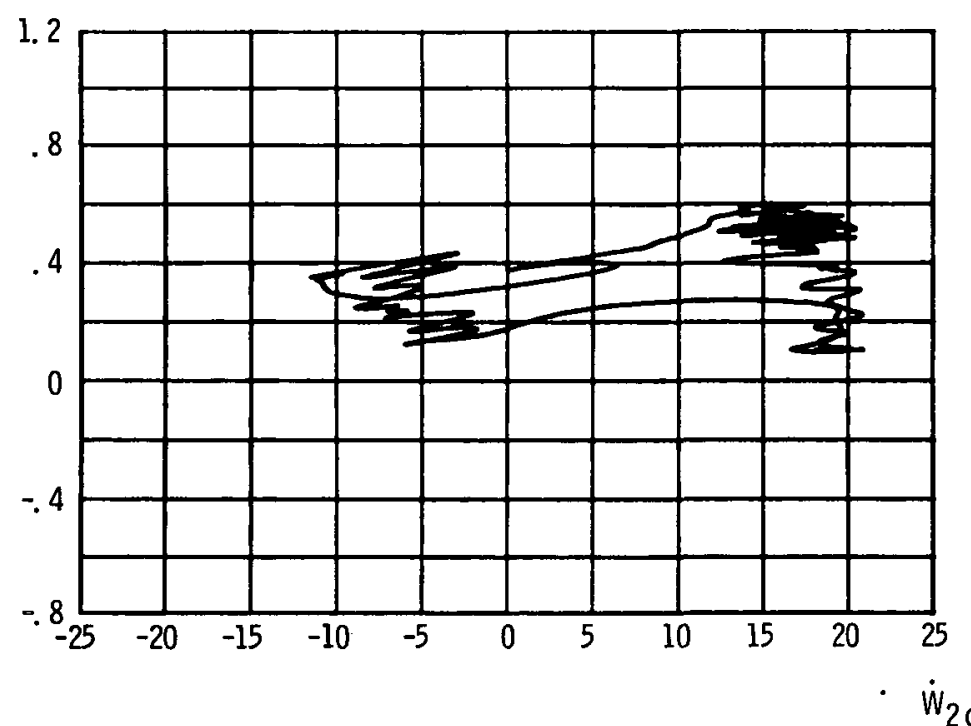

(d) Decreasing differentiator filter corner frequency; $F_{0}=$ $200 \mathrm{~Hz}$; $F_{d}=50 \mathrm{~Hz}$

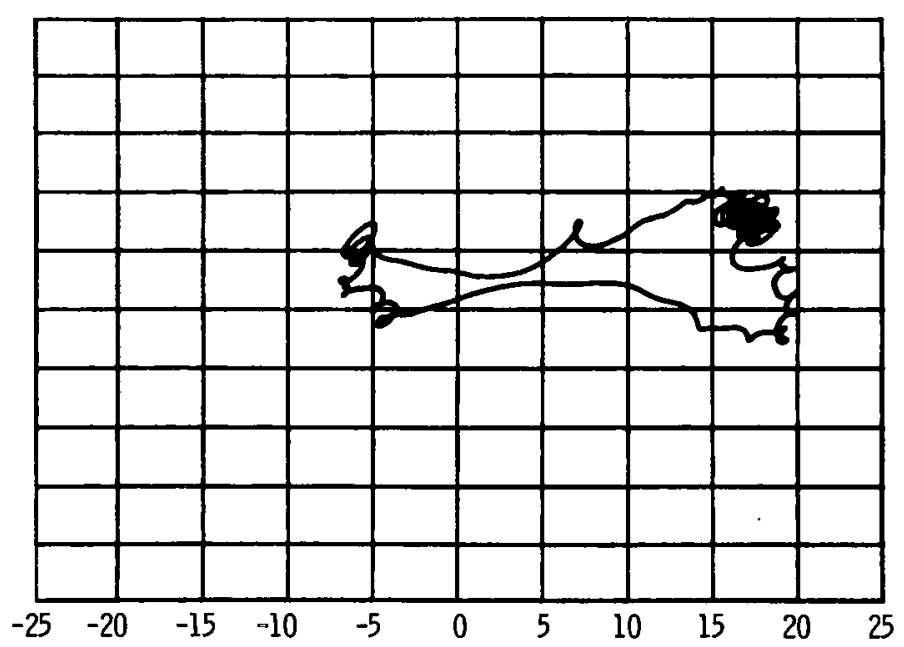

(e) Decreasing output filter corner frequencies; $F_{0}=50 \mathrm{~Hz}$; $F_{d}=400 \mathrm{~Hz}$.

Fig. 18. - Filter study. $\mathrm{N}_{\mathrm{C}}=86.6 \%$; cycle 14 . 


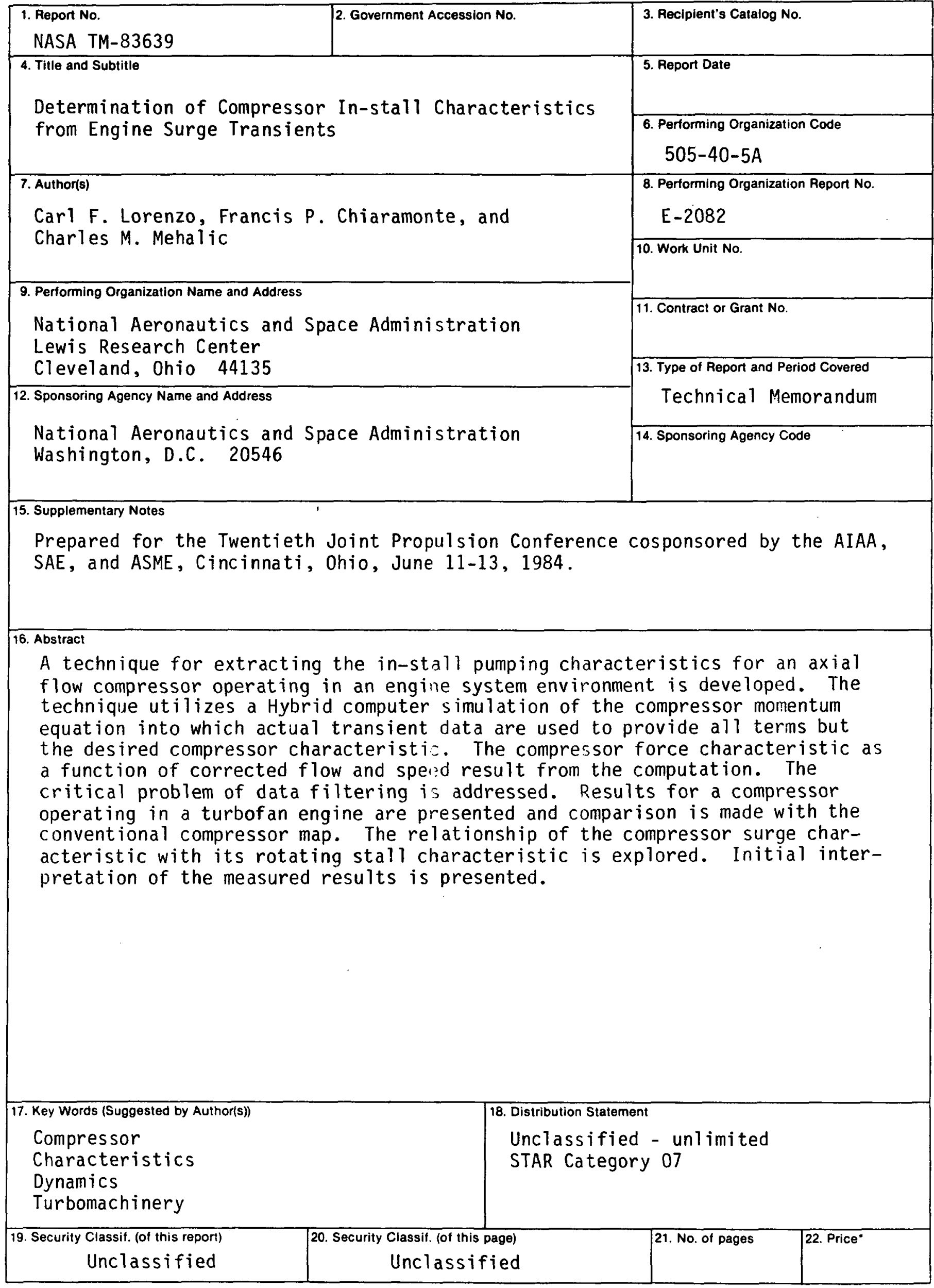

"For sale by the National Technical Information Service, Springfield, Virginia 22161 
National Aeronautics and

Space Administration

Washington, D.C.

20546

Official Business

Penalty for Privete Use, $\mathbf{5 0 0}$ seccial fountu class mall book

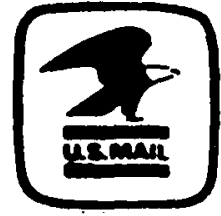

Poeteses and Fees Paid Netional Aeroneutics and Spece Administrotion MASA-451 